\title{
Nietzsche y el retorno romántico a la Naturaleza
}

\author{
MANUEL BARRIOS CASARES \\ Universidad de Sevilla
}

1.

Transcurridos varios meses desde el estallido de la polémica en torno a El nacimiento de la tragedia, cuando Nietzsche, apenas unos años atrás gran promesa de la filología clásica de su tiempo, acababa de ser declarado un autor 'científicamente muerto' por sus colegas de profesión y los acontecimientos estaban a punto de decantarlo hacia su más genuina vocación, la de filósofo como médico y crítico de la cultura, su principal maestro y valedor hasta entonces, Friedrich Ritschl, sumándose en privado al descontento general provocado por la 'ingeniosa borrachera' de su excepcional discípulo, escribió, sincerándose, a Vischer: «Es extraño cómo en este hombre viven realmente dos almas, una al lado de otra. Por una parte, el método más estricto de investigación científica especializada..., por otra, ese fanatismo religioso-mistérico-artístico, wagneriano-schopenhaueriano... que raya en lo incomprensible. [...] Lo que más me molesta es su impiedad para con su auténtica madre, que le ha amamantado en sus pechos: la filología».

Ya incluso en aquel momento Nietzsche podía haber respondido a la cortedad de miras de su apreciado mentor que eran mucho más de dos las almas que habitaban en su pecho. Ritschl no llegó nunca a comprender que fue por «fidelidad intempestiva» ${ }^{1}$ a un sentido más alto de la tarea destinada a aquella loba domesticada que lo había amamantado hasta la fecha, la filología, por lo que Nietzsche cometió la impiedad de proyectarla en una renovadora comprensión filosófica de la Antigüedad con valor para el presente. Sin duda, no lo hizo sin aporías ni contradicciones. Durante buena parte de sus años de errancia como espíritu libre, él mismo siguió dominado por la imagen de los

${ }^{1}$ Sobre el intento nietzscheano de transformación de la filología clásica en filosofía, cf. el capítulo «Deberes de una fidelidad intempestiva» del libro de Diego Sánchez Meca, En torno al superhombre. Nietzsche y la crisis de la modernidad, Barcelona: Anthropos, 1986, en especial las pp. 51-66, así como el estudio preliminar a su edición del curso dictado por Nietzsche en 1875, El culto griego a los dioses, Madrid: Aldebarán, 1999, pp. 11-47. 
dos compartimentos cerebrales, uno para la ciencia, otro para la no-ciencia, que debían tratar de coexistir en el alma moderna (HH: KSA II 208-209). Era ésta la nueva formulación, 'positivista' y desmitificadota, de lo que anteriormente había tratado de expresar con plasticidad poética a través de la polaridad de lo apolíneo y lo dionisíaco: una nueva formulación, que también se revelaría a la postre insuficiente para quien, desde su primer libro sobre los griegos, había tenido clara conciencia de estar 'pariendo centauros' al combinar filología y filosofía en sus textos de un modo tan íntimo y singular.

Pero probablemente sea en este rasgo donde resida el valor más apreciable del pensamiento nietzscheano, el de su impiedad e intempestividad, las cuales se ejercen en su caso por un declarado y firme deseo de no hurtar a la consideración ninguno de los matices y vertientes plurales que ofrece la existencia. Por eso yerran quienes se obstinan en petrificar el ritmo inquieto de este pensar en alguna de sus declaraciones más extremosas. Nietzsche es un pensador radical, que no reniega de pensar los extremos; pero no suele hacerlo de forma unívoca o unilateral, ni se contenta tampoco con su blando aquietamiento bajo una artificiosa medianía. En el estilo mismo de su escritura filosófica tiende a poner de relieve ese über, ese exceso o desbordamiento, que denuncia la profunda pereza intelectual, más aún, la atonía vital de toda pretensión de detenerse y descansar de una vez por todas en tierra firme, en un fundamento inconmovible. En cada uno de los tramos de su itinerario intelectual, Nietzsche ha sabido guardarse de esta tentación de la permanencia y ser siempre algo más: algo más que romántico en las formulaciones de su metafísica de artista; algo más que positivista en los vuelos de su librepensamiento. Ni la máscara del estricto investigador, que somete escrupulosamente los datos al supremo tribunal histórico-psicológico, ni la del visionario, que pretende revelar el misterio insondable de las cosas a través de las efusiones y arrebatos de su corazón, le cuadran si no es en el punto preciso en que este filósofo del disfraz las adopta con una intención eminentemente crítica y paródica. Hacer de Nietzsche, sin más, una especie de fisiólogo positivista de estirpe neokantiana o un profeta tardorromántico supone simplificar la compleja travesía de un pensamiento que ha cuestionado de forma decisiva la confianza ingenua del logos occidental en que un día no muy lejano alcanzaría al fin las costas del mundo verdadero. Nietzsche nos ha enseñado a entender de otro modo en qué consisten las Ítacas de nuestra demasiado humana historia multiversal, y esta enseñanza la ha ejercido ante todo prodigándose en el difícil arte de la despedida frente a los grandes metarrelatos modernos: no sólo frente al relato hiperracionalista del Progreso ineluctable de una Razón universal; también frente al relato ultrarromántico del Regreso al seno acogedor de una Naturaleza benevolente, de la que nunca debimos separarnos.

En concreto, me propongo tomar aquí esta temática de la vuelta a la Naturaleza como hilo conductor para abordar las complejas relaciones de sintonía y disonancia teóricas existentes entre ciertas formulaciones románticas y el pensa- 
miento nietzscheano. En el curso de esta aproximación, procuraré mostrar cómo el análisis de algunas ambigüedades y malentendidos que arrastra habitualmente la apelación al origen sugerida por determinados autores del llamado primer romanticismo alemán, o romanticismo temprano (Frühromantik), permite plantear la posibilidad de una línea de interpretación discrepante con la versión canónica que, de Rudolf Haym a Jürgen Habermas, ha solido cifrar en las acusaciones de irracionalismo, conservadurismo, así como de frívolo y narcisista subjetivismo una enmienda a la totalidad del programa romántico ${ }^{2}$. Al revisar de este modo los vínculos teóricos entre Nietzsche y el primer romanticismo, por fuerza ha de verse trastocada la óptica tradicional, que suele limitarse a contemplar la filosofía nietzscheana bajo un restringido prisma romántico. En lugar de ello, queda abierta así la vía para proyectar sobre una trama conceptual tan rica y polivalente como la de la Frühromantik esa comprensión más matizada de las ideas nietzscheanas en torno al binomio naturaleza-cultura.

Sea como fuere, ya con este mero planteamiento preliminar queda clara la necesidad de partir de una serie de distingos y precisiones, que la investigación especializada sobre Nietzsche viene teniendo presentes desde hace tiempo. En efecto: de ninguna manera puede hablarse de la relación entre Nietzsche y el romanticismo en un sentido unívoco. No hay una única relación, tal como no hay un único referente romántico. Bajo esta difusa adscripción se engloba a una amplia diversidad de ideas, obras, autores, concepciones artísticas y movimientos intelectuales de la cultura moderna europea, que trazan un arco temporal de más de un siglo de existencia, dentro del cual se suele datar sus inicios en las últimas décadas del siglo XVIII y su declive hacia finales del XIX. La fascinación primera de Nietzsche por el pesimismo metafísico de Schopenhauer y la Gesamtkunstwerk wagneriana, así como su posterior enfrentamiento al sesgo decadente de las concepciones de sus maestros de juventud, aun con ser determinantes del curso de su filosofía, no agotan desde luego lo laberíntico de su trato con los románticos. La controversia alcanza también a nombres como Victor Hugo, Delacroix, George Sand, Flaubert, los hermanos Goncourt o Baudelaire, entre otros, y se remonta asimismo a Rousseau. En cambio, suele dejar fuera a autores como Emerson, Heine, Shelley o Stendhal, citados con frecuencia, pero por lo general no conceptuados por él como románticos, al menos en un sentido peyorativo. Y, sobre todo, al margen de este combate nietzscheano contra los «resucitadores de muertos» (A: KSA III 145) queda el romanticismo temprano.

En un trabajo pionero, Karl Joël mostró ya la intensa afinidad de Nietzsche

\footnotetext{
${ }^{2}$ Haym, Rudolf, Die romantische Schule. Ein Beitrag zur Geschichte des deutschen Geistes, Hildesheim: Olms, 1961 (Berlin: Weidmann, 1870); Habermas, Jürgen, Der philosophische Diskurs der Moderne, Frankfurt: Suhrkamp, 1985 (tr. M. Jiménez Redondo, Madrid: Taurus, 1989, espec. pp. 109-134).
} 
con representantes de este movimiento como Novalis, Friedrich Schlegel o Ludwig Tieck ${ }^{3}$. También en las primeras décadas del siglo pasado, Charles Andler señaló los paralelismos argumentales existentes ${ }^{4}$. Con posterioridad, ha sido Ernst Behler, entre los estudiosos de Nietzsche, uno de quienes más ha insistido en la importancia de dicho nexo, sosteniendo de manera convincente que la crítica nietzscheana a los románticos no sólo no incluye a esta primera forma particular del romanticismo alemán, sino que incluso se nutre de nociones, temas y recursos teóricos generados en tal contexto, alrededor de los años de 1795 a 1800, para denunciar en la Spätromantik representada por Schopenhauer o Wagner una deformación de los principios inspiradores de esta escuela ${ }^{5}$. Argumenta Behler en ese sentido que la tipología del romanticismo denostado por Nietzsche se concreta fundamentalmente en tres grandes rasgos, atribuibles todos ellos a las concepciones predominantes a lo largo del siglo XIX, pero sólo aplicables al primer romanticismo de una forma sesgada. Dichos rasgos serían: la asimilación del temperamento romántico a la enfermedad, patente en el gusto por lo morboso y en el predominio de un profundo sentimiento de cansancio, de desgana de vivir, que requiere por tanto de remedios artificiosos y de fuertes excitantes para poder reanimarse; el desprecio de la razón, con el consiguiente repudio de la mentalidad ilustrada; y, en tercer lugar, la fijación nostálgica en el pasado, plasmada de modo ejemplar en la idealización del mundo cristiano-medieval como base para la promoción de un clericalismo católico y una actitud políticamente reaccionaria, decididamente hostil a las fuerzas del progreso. Otros elementos como el nacionalismo o la actitud escapista de complacencia en exotismos varios podrían considerarse igualmente expresiones de esta voluntad extenuada, cuya impotencia para transformar el mundo real la

${ }^{3}$ Joël, Karl, Nietzsche und die Romantik, Jena-Leipzig, 1905.

${ }^{4}$ Andler, Charles, Nietzsche. Sa vie et sa pensée, 6 vols., París: Gallimard, 1920-1931, en especial vols. I y II.

${ }^{5}$ Cf. Behler, Ernst, «Nietzsche und die Frühromantische Schule», Nietzsche-Studien 7 (1978), p. 67. Véase también «Die Kunst der Reflexion. Das frühromantische Denken im Hinblick auf Nietzsche», en AA. VV., Untersuchungen zur Literatur als Geschichte, Berlín: Schmidt, 1973, pp. 219-248.

${ }^{6}$ «En el fondo, la música de Wagner no es sino literatura, como todo el romanticismo francés: el encanto del exotismo, de épocas, costumbres y pasiones extranjeras actuando sobre horteras sensibles; el arrebato experimentado al introducirse en aquel indescriptible país lejano, extranjero y antiquísimo, al cual se accede por medio de libros que pintan todo el horizonte con nuevos colores y posibilidades... El presentimiento de mundos aún más lejanos y de acceso todavía sellado; el 'dédain' hacia los 'boulevards'... El nacionalismo, y nadie debe engañarse, no es sino una forma particular de exotismo... Los músicos románticos cuentan lo que los libros han hecho de ellos: se querría experimentar cosas exóticas, vivir pasiones de gusto florentino o veneciano: al final, se contenta uno con buscarlas en la imaginación... Lo esencial es el género de deseos nuevos, un querer-imitar y un querer-vivir-imitando, el disfraz, la disimulación del alma... El arte romántico es sólo un recurso necesario ante una 'realidad' fracasada» (KSA XIII 494: 16[34], primavera-verano de 1888). 
induce a la mayor extravagancia en el ansia de sentir cosas nuevas ${ }^{6}$.

Observa además Behler que, aun cuando autores como Goethe, Hegel o Heine han atribuido características semejantes a miembros de la primera escuela romántica, sin embargo, y pese a compartir las directrices esenciales de esta crítica, que se sustancia en el dictamen goetheano «llamo clásico a lo sano, y romántico a lo enfermo», Nietzsche no se ha mostrado nada proclive a localizar en ellos tales rasgos ${ }^{7}$. Cuando habla de un esteticismo de nigromantes, que se deleita en el anhelo de muerte y la renuncia a la vida, no piensa en Novalis, sino en Richard Wagner y en el decadentismo francés. Cuando prolonga los dicterios de Hegel contra esa subjetividad descontrolada e irresponsable, que abandona a la razón en favor del sentimiento, no alude, como aquél, a Friedrich Schlegel, sino a Rousseau. Cuando denuncia que todos los románticos terminan igual, postrados ante la cruz, aunque podría estar pensando también en Friedrich Schlegel por su conversión final al catolicismo, no se refiere de manera explícita a él, sino de nuevo a Wagner.

A estas alturas, no cabe tampoco aducir desconocimiento o poca familiaridad con los textos de los primeros románticos. Desde sus años de formación en la escuela de Pforta, Nietzsche adquirió, junto con una sólida base para su posterior dedicación a la filología clásica, suministrada por profesores como Wilhelm Corssen o Karl Steinhart, un amplio conocimiento de la literatura alemana del siglo precedente $^{8}$. Su profesor de historia de la literatura, August Koberstein, propició un contacto de primera mano con la obra de autores como Lessing, Goethe o Schiller, así como con la de los hermanos Schlegel o Novalis, y tampoco pudo impedir que su joven estudiante le dedicase un trabajo encomiástico al entonces relegado Friedrich Hölderlin, en el que demostraba un extenso conocimiento y una sutil comprensión de las ideas de su 'poeta preferido'. Más tarde, cuando Nietzsche emprendió los estudios universitarios en Bonn, su maestro, Friedrich Ritschl, que a la sazón había compartido con August Wilhelm Schlegel años de vida académica en aquella universidad, le facilitó un mayor acercamiento a toda esa atmósfera intelectual -una atmósfera que había sido capaz de dotar

${ }^{7}$ Cf. Behler, E., op. cit., pp. 67-69.

${ }^{8}$ Mazzino Montinari resume así las líneas básicas de esta formación: «El aprendizaje del método histórico-crítico en la lectura de textos, un conocimiento directo y bastante amplio de los autores más importantes de la antigüedad grecolatina y el perfeccionamiento asiduo del estilo, para el cual Nietzsche toma como modelo a Salustio, hay que situarlos en estos seis años de estudios de Pforta. Durante ese mismo periodo se perfila su distanciamiento de la religión de sus padres. Entre los autores modernos que figuran con más frecuencia en las lecturas y los apuntes de esta época encontramos a Emerson, Sterne, Byron, Schiller, Goethe, Hölderlin, Novalis, Kerner, Platen, Cervantes, Alexander von Humboldt y también La esencia del cristianismo de Ludwig Feuerbach, la Historia de la literatura del siglo XVII de Herman Hettner (1856-1870) y obras historiográficas como la Historia de la Revolución Francesa de Eduard Arnd (1851)» Che cosa ha veramente detto Nietzsche, Milano: Adelphi, 1975, p. 28. (tr. E. Lynch, Barcelona: Salamandra, 2003, pp. 32-33). Cf. también Andler, C., op. cit., II, 50. 
a las estribaciones del debate en torno a antiguos y modernos de una inflexión decisiva en su rumbo. En efecto: tras la estela de los 'germanistas', precursores en la toma de conciencia de una identidad nacional, y desde un espacio compartido con el clasicismo de Weimar, este singular conjunto de literatos, dramaturgos, poetas y estetas del romanticismo temprano se propuso revisar a fondo los periclitados modos en que la Ilustración había venido concibiendo hasta entonces su referencia paradigmática al pasado grecolatino como modo de legitimación del presente. De esta forma desplazó el sentido de aquella centralidad del mundo 'clásico', sin dejar por ello de constituirse en uno de los grandes impulsores de los estudios histórico-filológicos de la Antigüedad. Mediante esa otra mirada lanzada a lo antiguo, que acertó a descubrir, tras la serenidad olímpica, remotos impulsos a la desmesura y la disolución como los que volvían a pujar en la propia época, el primer romanticismo conformó así aquella tradición de la Sachphilologie, de la que tan intensamente hubieron de nutrirse algunas de las tesis de El nacimiento de la tragedia ${ }^{9}$.

No obstante, la filología romántica había quedado relegada de los ámbitos académicos cuando Nietzsche dio a la imprenta su libro sobre los griegos. El propio Ritschl, dando muestras de una injusta y profunda incomprensión hacia los presupuestos filosóficos del trabajo de su discípulo, había acabado cediendo a los planteamientos oficiales de la filología clasicista del momento, pese a tantos puntos de contacto como habían existido entre sus concepciones de la literatura y el mundo griegos y las de autores como Friedrich Schlegel. Nietzsche fue presentado por su ambicioso colega y rival, Ulrich von Wilamowitz-Möllendorff, como un genio aislado y extravagante, seducido por el orientalismo y el budismo schopenhauerianos. En su panfleto, Wilamowitz se cuidó de citar a autores como Schelling, Friedrich Schlegel, Görres, Bernays o Bachofen, aludió de pasada a otros como O. Müller y sólo mencionó una vez, en tono francamente despectivo, a Friedrich Creuzer. Era otro modo de desacreditar al joven catedrático de Basilea, obviando a precursores tan influyentes en su elaboración de la antítesis entre lo apolíneo y lo dionisíaco ${ }^{10}$. El propio Nietzsche, debido a un excesivo prurito de originalidad, al aire exaltado de su escrito y a su puesta en escena como épico pensador, en combate solitario contra la cultura, contribuyó en gran medida a sembrar la confusión al respecto. Aun así, todavía en aquellos años era un secreto a voces que sus ideas de Nietzsche

\footnotetext{
${ }^{9}$ Para un tratamiento más detallado de la cuestión de las relaciones entre el joven Nietzsche y la filología romántica, además del trabajo pionero de Howald, Ernst, Friedrich Nietzsche und die klassische Philologie (Gotha, 1920), y de la inestimable aportación de Baeumer, Max L., «Das moderne Phänomen des Dionysischen und seine 'Entdeckung' durch Nietzsche», Nietzsche-Studien, 6 (1977), pp. 123-153, me permito remitir a los capítulos IV y V de mi estudio Voluntad de lo trágico. El concepto nietzscheano de voluntad a partir de El nacimiento de la tragedia (Madrid: Biblioteca Nueva, 2003²).

${ }^{10}$ Hay edición en castellano de los textos de la polémica, a cargo de Luis de Santiago Guervós: Nietzsche y la polémica sobre El nacimiento de la tragedia, Málaga: Ágora, 2004.
} 
sobre la cultura griega y la manera en su obra se había posicionado frente a las tesis de la filología clasicista de su tiempo lo emparentaban directamente con la herencia del primer romanticismo.

Por consiguiente, una evidencia se impone: al apartarse de la órbita intelectual de Schopenhauer y Wagner, condenando el romanticismo implícito en sus concepciones, Nietzsche no estimó necesario incluir en dicha condena a los autores de la Frühromantik, a quienes conocía bien y de quienes tan cercano se había sentido desde un primer momento. Por el contrario, puede afirmarse que fue más bien la radicalidad y perseverancia con la que Nietzsche acogió este legado lo que le llevó a polemizar con la desviación pesimista y decadente representada por los mentores de su juvenil 'metafísica de artista'. No obstante, las descalificaciones de Nietzsche como pensador antimoderno, añorante de un orden perdido y festejador irracionalista de la fuerza bruta, que todavía hoy se siguen reiterando, suelen pasar por alto los términos explícitos de esta controversia; o bien difuminan por completo el sentido de su relación con el ideario de la Frühromantik. De esa manera, desatienden el hecho de que, en Nietzsche, la crítica genealógica de la razón se gesta propiamente a partir de un ajuste de cuentas con el repudio nihilista-tardorromántico de toda forma de racionalidad. Asimismo, oscurecen la evidencia de que también puede hallarse un rotundo rechazo del abandono irracionalista en los místicos barruntos del alma romántica, una denuncia de su decadentismo y de su mentalidad reaccionaria en los textos nietzscheanos de madurez ${ }^{11}$.

Es cierto que Nietzsche intensifica el reconocimiento del carácter situado de la razón-i. e., su indisoluble vinculación a estratos prerreflexivos de la existenciahasta un límite que resulta intolerable para aquellos nostálgicos de la razón transparente, que se empecinan en hacer de una de sus específicas configuraciones históricas un referente cuasitranscendental, con aspiraciones normativas de validez universal. Pero en esta tarea tampoco deja de ser fiel al empeño del romanticismo

${ }^{11}$ Contra el pesimismo y el decadentismo románticos, vid. el prefacio a la segunda edición (1886) de La gaya ciencia y el importante aforismo 370, titulado «¿Qué es romanticismo?». Sobre el conservadurismo schopenhaueriano como un estímulo, no para regresar al cultivo de las antiguas necesidades metafísicas, sino para poner a prueba la fortaleza de las nuevas orientaciones, revisar el pasado y, tras corregir las estrecheces de la concepción historicista aportada por el Siglo de las Luces, «enarbolar de nuevo la bandera de la Ilustración», cf. el aforismo 26 de Humano, demasiado humano, «Reacción como progreso». Sobre el arte sin presupuestos metafísicos, ibid., aforismo 222, «Lo que queda del arte».

${ }^{12}$ Resumo en esta nota, en términos de controversia con Habermas, unos de los hilos argumentales del presente artículo. Para Nietzsche, la base a partir de la cual la razón humana se emancipa de su anclaje en un mundo vital de pasiones e intereses es siempre una base precaria, lábil, tejida por el hábito y la creencia, por acuerdos pragmáticos y presuposiciones tanto más arriesgadas cuanto más idealizantes, incapaz por tanto de dar pábulo a la confianza racionalista en una autofundación de su proceder. La razón tiene que operar bajo condiciones nunca determinadas del todo ni plenamente esclarecidas por ella de antemano. Pero esto no la destituye por completo de su función orientadora. Al contrario: ya desde El nacimiento de la tragedia, Nietzsche se 
temprano en retomar y completar el proyecto ilustrado ${ }^{12}$. Sería oportuno, por tanto, revisar el prejuicio interpretativo que lee en muchas de las manifestaciones nietzscheanas del llamado 'período intermedio' de su pensamiento una simple reacción pasajera de rechazo de sus más firmes convicciones de antaño, a las que, no obstante, más tarde se limitará a regresar con un acento más personal, renovando sus votos románticos e irracionalistas de juventud. Habría que tomarse más en serio la ‘ilustración' de Nietzsche, considerando hasta qué punto no ha tratado el filósofo de desandar el camino hacia las fuentes de su primera inspiración, esto es, hacia aquel proyecto de una 'Ilustración superior', que no rechaza el papel crítico de la razón, como no lo hace el Nietzsche de Humano, demasiado humano, pero que lo extiende a sus propios productos, relativizando el alcance de una imagen científica del mundo de corte puramente positivis$\mathrm{ta}^{13}$. El itinerario nietzscheano de madurez, marcado por la recuperación de la función afirmativa del arte una vez despojado de sus ínfulas metafísicas, en

preocupa seriamente por el despliegue de una racionalidad desmedida, dispuesta a consumirse en una duda hamtletiana al sentirse desprovista de bases firmes para resolverse en un sentido u otro, y trata de remediar su hybris autodestructiva. Así pues, la crítica autorreferencial de una razón que se consume a sí misma en el movimiento de su duda y desfundamentación la comprende Nietzsche de una manera muy diferente a como lo hace Habermas. Podría verse aquí una cierta similitud con el estilo de la crítica hegeliana a la ironía romántica, ya que lo que Nietzsche observa es que esta autoconsunción viene impuesta precisamente por las pretensiones de absolutez y autofundamentación de la racionalidad propias de la cultura alejandrina, que se ha separado tanto de su sustrato mítico, festivo, erótico y vivencial, es decir, que ha hecho tal abstracción de sí, que no encuentra el modo de conectarse con el mundo y apostar por él si no es desde una certeza incontrovertible. Al no ser capaz de dar razón plena del sentido una vez quebrado su optimismo metafísico, deja fija la mirada en lo imposible de esclarecer. Esta vuelta sobre sí es, por tanto, realmente autodestructiva en cuanto a implicaciones vitales se refiere. La razón desarraigada puede entonces someter tanto a la naturaleza externa cuanto a la interna a la total colonización del mundo de la vida. El joven Nietzsche entiende por el contrario, que cuando la lógica se enrosca sobre sí misma y acaba por morderse la cola, es cuando una cultura, al objeto de no quedar fagocitada por semejante movimiento reactivo de superfetación de lo lógico, debe volverse hacia el reconocimiento trágico de la inconceptuabilidad última de la existencia; pero entiende también que esta asunción de los límites no tiene por qué expresarse de manera puramente negativa; sino que puede afirmarse placenteramente a través de la experiencia artística, en la cual el sinsentido, el caos, se transfiguran en tanto que ocasión para la creación de nuevas formas. Esta crítica a la soberbia de una razón ultrarradicalizada desplaza, pues, a otro terreno aquella aporía que Habermas se empeña en resolver sin éxito en un ámbito de transparencia reconquistada (tanto más aporético en la medida en que combina la añoranza de una fundamentación fuerte de la razón en su absoluta autonomía con la convicción de su impotencia actual para lograr tal cosa). Nietzsche practica esa vuelta sobre sí de la razón en términos genealógicos.

${ }^{13}$ Sobre este punto, vid. mi estudio preliminar a la edición castellana de Humano, demasiado humano, tr. A. Brotons, Madrid: Akal, 1996, vol. I, pp. 7-27. La idea de una «Ilustración superior» proviene de la obra de Hölderlin. Cf. Sämtliche Werke und Briefe (SWB), ed. G. Mieth, Darmstadt: Wissenschaftliche Buchgesellschaft, ${ }^{5} 1989$, vol. I, p. 861. Uno de los títulos pensados por Nietzsche para Más allá del Bien y del Mal, su «preludio de una filosofía del futuro», fue el de «La nueva Ilustración» (KSA XII 34). 
tanto movimiento opuesto al nihilismo reactivo y factor de crítica de la cultura, aparece así a la luz de una coherencia y una continuidad bien distintas a las que suelen atribuírsele. De hecho, si dejamos a un lado la fascinación personal por Wagner y esa pasión por la música, compartida igualmente con Schopenhauer, que le lleva a tomarla como ámbito distinguido de una experiencia más intensa del mundo, hay que decir que lo que liga a Nietzsche con sus dos más famosos maestros de juventud es, sobre todo, aquello que en la obra de ambos conserva aún el eco de la protesta de los jóvenes idealistas y primeros románticos contra la excesiva abstracción y falta de vitalidad del concepto ilustrado de razón.

Por ejemplo, la admiración por la cultura trágica de los griegos y su adopción como modelo opuesto al alejandrinismo de la civilización moderna son elementos fundamentales del pensamiento nietzscheano de juventud, que sólo poseen un pálido reflejo en algunas consideraciones de Wagner y un lugar bastante más secundario en la obra de Schopenhauer. Wagner mantiene una relación más superficial, muy intelectualizada, con el mundo griego: apela a él como base argumental de sus textos en ocasiones, se nutre y beneficia de los paralelismos enunciados por Nietzsche, pero no cuenta en absoluto con el horizonte dionisíaco de la grecidad a la hora de sustentar el complejo mítico-legendario de sus óperas. En cuanto a Schopenhauer, resulta indiscutible el privilegio concedido a la tragedia moderna frente a la antigua por lo que se refiere a su capacidad de mostrar lo irremediable del dolor y lo absurdo de la existencia ${ }^{14}$; de modo que esta postergación de lo griego marca desde el principio una neta distancia con el joven Nietzsche. Pero, por encima de todo, la consideración nietzscheana de la nueva obra de arte trágica como vehículo privilegiado de formación y transformación cultural constituye un aspecto inexistente en la estética schopenhaueriana, que en cambio enlaza de modo directo con los sucesivos proyectos de cumplimentación de la ilustración que Aufklärer y Frühromantiker habían venido formulando en suelo alemán desde finales del XVIII, en su siempre renovado intento de dar solución al problema de la 'nación dividida' ${ }^{15}$. En concreto, los términos en que Nietzsche concibe el tenso ajuste entre sobriedad apolínea y desbordamiento dionisíaco recuerdan inequívocamente a los de la propuesta protorromántica de una 'mitología de la razón': devolver el logos a su fuente mitopoiética (Novalis, F. Schlegel), replicar a la barbarie de la reflexión moderna con una 'ilustración más elevada' (Hölderlin), conjugar las fuerzas creadoras del ser humano en la obra de arte de la tragedia (A. W. Schlegel),

${ }^{14}$ Como ya se encargó de subrayar convenientemente el estudio de Walter Kaufman, Tragedy and Philosophy, New York: Doubleday, 1968 (Barcelona: Seix-Barral, 1978), centrando su atención en los añadidos de Schopenhauer al libro tercero de El mundo como voluntad y representación.

${ }^{15} \mathrm{Cf}$. al respecto el excelente trabajo de Félix Duque, «Nietzsche y la arqueología 'romántica' de la cultura », en La estrella errante. Estudios sobre la apoteosis romántica de la Historia, Madrid: Akal, 1997, pp. 75-122. 
reencantar el mundo sin renunciar al ejercicio de la crítica... Según aparece plasmada toda esta aspiración en el fragmento denominado El más antiguo programa de sistema del idealismo alemán ${ }^{16}$, el pensamiento de una cesura fuerte, metafísica, entre lo sensible y lo inteligible, entre naturaleza y espíritu, entre mito y razón, ya no rige aquí. La 'nueva mitología' preconizada por los camaradas de Tubinga -Hegel, Hölderlin, Schelling- no pretende sustituir el concepto racional por la intuición, sino 'hacer sensibles' las ideas, tornarlas 'estéticas', sin que por ello dejen de seguir orientando la acción del hombre en el mundo. «La poesía vuelve a ser lo que era al principio, maestra de la humanidad»; pero no porque se regrese a un estadio anterior de la cultura, sino porque se asciende hasta «el acto más elevado de la razón», que es el 'acto estético' de conjunción de las diferentes facultades humanas. Se habla ahí también de una «Física superior», capaz de pensar el mundo de una manera no mecanicista, sino conforme al carácter de espontaneidad de la voluntad humana; y la naturaleza misma, al igual que los productos del espíritu, es contemplada como un proceso dinámico que constantemente se reorganiza en formas vivientes complejas, disolviendo configuraciones pasadas e ingeniando otras nuevas. Por su parte, el «Discurso sobre la mitología» ${ }^{17}$, incluido por F. Schlegel en su Diálogo sobre la poesía (1800), reitera uno a uno estos puntos: los modernos aún «no tenemos una mitología», aunque «estamos cerca de tener una, o, mejor, [...] debemos colaborar seriamente para crear una». Pero ésta ya no será, como la antigua, producto de la 'joven fantasía', adherida inmediatamente a lo sensible. «Sólo podrá surgir de la profundidad más honda del espíritu». De ello «hallamos un indicio muy importante y una notable confirmación en el gran fenómeno de la época, el Idealismo», en tanto muestra del «espíritu de aquella revolución» que comienza ya a operar también en la Física, «a la cual parece no faltar más que una visión mitológica de la naturaleza». Invocando el nombre de Spinoza para referirse al pensamiento de la conjunción de lo espiritual y lo sensible (o de idealismo y realismo), Schlegel califica a esta nueva creación mitopoiética de «obra de arte de la naturaleza» y añade que, siendo «la más artística de todas las obras de arte», deberá englobar a todas las demás y configurarse como «un nuevo lecho y recipiente para la antigua eterna originaria fuente de la poesía y el infinito poema mismo que guarda los gérmenes de todos los poemas», dado que mitología y poesía constituyen «una unidad indivisible».

Pues bien, hay un factor de capital importancia para entender hasta qué

${ }^{16}$ SWB I 917-919. Como es sabido, la autoría del texto sigue siendo asunto debatido, habiendo sido atribuida tanto a Schelling como a Hölderlin o Hegel, e incluso a algún otro pensador de su círculo. Cf. v.g. Henrich, Dieter, Konstellationen. Probleme und Debatten am Ursprung der idealistischen Philosophie (1789-1795), Stuttgart: Klett-Cotta, 1991.

${ }^{17}$ Cf. Kritische Friedrich Schlegel Ausgabe (KA), ed E. Behler, J. J. Anstett y H. Eichner, Padeborn: Schöndig, 1958ss., vol. II, pp. 317ss. Hay trad. cast. de D. Sánchez Meca y A.I. Rábade en Schlegel, F., Poesía y Filosofía, Madrid: Alianza, 1994, en espec., pp. 118-121. 
punto Nietzsche ha heredado y modulado todos estos planteamientos, comunes a los jóvenes idealistas de Tübingen y a los primeros románticos; y es su condición de réplica al problema del nihilismo de lo sensible advertido por Friedrich Heinrich Jacobi en su lectura de la nueva filosofía postkantiana como una suerte de spinozismo encubierto. Es un hecho ya sobradamente conocido por la investigación histórico-filosófica especializada que los orígenes de la discusión sobre el nihilismo se remontan a ese período germinal del idealismo alemán, en el que la joven generación se vio conmocionada por las revelaciones de Jacobi en sus Cartas al señor Moses Mendelssohn sobre la doctrina de Spinoza, detonantes de la famosa «disputa del panteísmo» ${ }^{18}$. Sin embargo, no se ha insistido aún lo suficiente en la obvia conexión existente entre la manera en que estos autores encararon el reto del nihilismo y la forma en que lo hizo Nietzsche ${ }^{19}$. La noticia de que un pensador ilustrado del prestigio del entonces recién desaparecido Lessing había hecho una explícita profesión de fe panteísta - «Los conceptos ortodoxos de la divinidad no son para mí; no puedo sacar provecho de ellos. ¡Hen kaí pan! Otra cosa no sé» ${ }^{20}-$ y el argumento de que toda la crítica de la metafísica desplegada por la razón moderna no podía conducir sino a la liquidación de la consistencia del mundo sensible, reducido a mera ilusión aparente al haber suprimido a Dios como su fundamento, no obraron en los jóvenes idealistas el efecto deseado por su promulgador. Ni siquiera cuando la nueva arremetida de Jacobi en 1799 -en que ya usó expresamente el término 'nihilismo', como sinónimo de idealismo, quimerismo y ateísmo-acabó con la expulsión de Fichte de su cátedra de Jena, éstos se arredraron. No se aplicaron, pues, como Jacobi, a restaurar el viejo orden perdido del mundo metafísico mediante un salto mortale hacia la creencia y la 'no-filosofía'; sino que apostaron por un nuevo modo de pensar ese único mundo que les había quedado. Aceptaron ciertamente la necesidad de ir más allá de las representaciones de lo real elaboradas por un intelecto completamente desligado de la intuición, la fantasía y la imaginación. Pero fueron ellos, antes que Nietzsche, quienes intentaron inmanentizar ese 'más allá', ese über, procurando extraerlo del humus mismo del ámbito carnal y espiritual, viviente y mortal, en que habitamos. Tradujeron por tanto la intuición jacobiana de un ente sobrenatural a una versión del «fructífero campo de la experiencia sensible», que desbordaba los límites de la discursividad finita del entendimiento kantiano. Los dioses, no hacién-

${ }^{18}$ Jacobi, F.H., Ueber die Lehre des Spinoza, in Briefen an den Herrn Moses Mendelssohn (1785; 1789), en Werke. Gesamtausgabe der Bayerischen Akademie der Wissenschaften, edición dirigida por K. Hammacher y W. Jaeschke, vol. 1: Schriften zum Spinozastreit, ed. K. Hammacher e I.-M. Piske, Hamburg/Stuttgart-Bad Canstatt: Meiner/Fromman-Holzboog, 1998. Hay trad. cast. de J.L. Villacañas, Cartas a Mendelssohn. David Hume. Carta a Fichte, Barcelona: Círculo de Lectores, 1996.

${ }^{19}$ Trabajo precursor en esa línea fue el de Arendt, Dieter, Nihilismus. Die Anfänge von Jacobi bis Nietzsche, Köln: Hegner, 1970.

${ }^{20}$ Jacobi, op. cit., p. 16; cf. ed. cast., p. 88. 
dose más pobres ni más bajos por ello, debían encarnar en la tierra y morar en ella, escribió un joven romántico de aquella época llamado Hegel, aceptando entonces el envite trágico de que, así las cosas, para realizar el «Reino de Dios en la tierra», no habría más remedio que pasar por el duro trance y experiencia de lo negativo, muerte de Dios incluida ${ }^{21}$. Ya ellos pudieron decir, así pues, antes que Nietzsche, que el nihilismo resultaba un fenómeno ambiguo: la noche de la ausencia de los dioses podía ser experimentada como puro desierto de lo real extendido por doquier. Era ésa la modalidad reactiva de vivencia nihilista que -en esto daban parcialmente la razón a Jacobi- había que combatir. Mas también cabía columbrar, en medio de toda esta experiencia de desasimiento, la posibilidad de recrear el sentido de la tierra. El nihilismo podía leerse a su vez en clave activa, como ocasión para desustancializar la costra del realismo dogmático y, revolucionando los modos habituales de captación y expresión del orden fenoménico, hacer aflorar otra dimensión de lo real, dotando de plenitud ontológica a la apariencia. La crítica a la reducción mecanicista de la imagen del mundo -capaz sólo de verlo como mundo de la necesidad, sometido de manera fatalista a la condena del «así fue, así será» -había de ser precisamente lo que diera paso a la nueva visión de la Naturaleza, anticipada por Goethe, como un organismo con vida propia y creatividad desbordante, inaprehensible bajo los parámetros meramente cuantitativos del matematicismo imperante hasta entonces.

Es esto, por ejemplo, lo que anima el programa de una Naturphilosophie en Schelling, donde las fuerzas inconscientes de la naturaleza constituyen una manifestación más de esa libertad que, en el espíritu humano, se plasma de forma señera en la obra de arte. Hegel interpretará después dicha manifestación como un anticipo, como un oscuro presagio del concepto, que a la postre tendrá que salir a la superficie y revelarse plenamente en su transparencia lógica. En el contexto del primer romanticismo, sin embargo, no cede tan fácilmente la convicción de que ese fondo último de la naturaleza permanece en su condición abismática. Y así, una naturaleza que la ‘fría razón' había opuesto al hombre, que había considerado como pura materia inerte y extraña a la libre actividad del sujeto, susceptible en consecuencia de manipulación, dominio y explotación por parte de éste, se dota ahora

${ }^{21}$ En el escrito $\mathrm{Fe}$ y saber, a propósito de su debate con las filosofías de la reflexión (Kant, Fichte, Jacobi), Hegel recurre a la imagen de la muerte de Dios para referirse al final de la abstracción metafísica, calificado ahí como «Viernes Santo especulativo», y derivar de él la necesidad de que el principio de lo infinito resucite y encarne definitivamente en lo terreno. En 1862, el joven escolar de Pforta manifiesta ya su proximidad a este planteamiento: «Si Dios se hizo hombre, eso significa sencillamente que el hombre no debe buscar su propia beatitud en el infinito, sino fundar su cielo en la tierra; la ilusión de un mundo ultraterrenal indujo a los hombres a asumir una posición equivocada con respecto al mundo terrenal: esto fue resultado de la infancia de los pueblos. [...] Entre graves dudas y luchas la humanidad se hace fuerte: reconoce en ella misma el principio, el centro y el fin de la religión» Nachgelassene Aufzeichnungen, II, Berlin: de Gruyter, 2000, fragmento 13[8], en KGW, sección I, editada por Hans Gerald Höld e Ingo W. Rath. 
de una nueva extrañeza, que comienza a proyectarse sobre la comprensión misma del ser humano. Un autor tan determinante en esta nueva constelación intelectual como es el caso de Hölderlin, el 'poeta preferido' del joven Nietzsche, ha expuesto de manera ejemplar esta temática en su Hiperión. Naturaleza no es simplemente objeto, una entidad puesta frente a la conciencia. Es el signo con el que Hölderlin apunta a esa indescifrabilidad última del mundo, que él piensa ya como unidad concordante en la discordancia desde sus primeras apelaciones al amor como una fuerza cósmica de estructuración del caos primigenio ${ }^{22}$. Este «ser, en el sentido único del término ${ }^{23}$ no puede seguir siendo concebido según los patrones de la subjetividad autorreflexiva (como una 'identidad', pues), ni puede ser principio absoluto de deducción de todo lo real, tal como postula la Doctrina de la ciencia fichteana. En esbozos ensayísticos como «Juicio y Ser» (1795) se documenta este punto de inflexión del idealismo, donde la quiebra del fundamento, del Satz vom Grundes, va adquiriendo un cariz trágico, que luego Nietzsche se encargará de acentuar. Ya el joven Hölderlin asume aquí, a través de su temprana crítica a Fichte, la renuncia a un punto de partida absoluto, indubitable y autoevidente como el del yo cartesiano. En lugar de ello, se está en la escisión, y es desde ella desde donde cabe intuir otro régimen posible de relación con el mundo, previo a las formas de la dominación que segrega la estructura dualista del entendimiento. Hölderlin afirma además en reiteradas ocasiones que la aproximación a esa concordancia previa es infinita, es decir, que no puede darse nunca de hecho una restauración de la presunta unidad original. Si ésta se da, es justamente al modo de una ausencia que regula el sentido de nuestra conducta teórica y práctica. Mientras Schelling y Hegel se afanan aún por aquellos años en pensar un principio efectivamente existente, que reúna nuestro saber y nuestro obrar, Hölderlin ha comenzado ya, en ese sentido, a despedirse del idealismo. Nietzsche no hará sino incidir en esa extrañeza, haciendo que el más inquietante de todos los huéspedes venga a albergarse también en las otrora hogareñas estancias de la physis.

2.

Por mucho que la investigación histórico-filológica nos demuestre que Nietzsche ha leído tardíamente el vocablo ‘nihilismo' en los nihilistas rusos o en los

${ }^{22}$ Cf. SWB I 117-121. La misma idea, procedente de la cosmogonía de Empédocles, se halla en el «Discurso sobre la mitología» de F. Schlegel, en referencia a la productividad del desorden que arrastra la nueva mitología al tener que englobar las diferentes formas artísticas precedentes: «La suprema belleza, así como el supremo orden sólo son propiamente los del caos, un caos que únicamente espera el contacto del amor para desplegarse en un mundo armónico, un caos como lo fueron también la antigua mitología y la antigua poesía» (KA II 318). Sobre la importancia de la figura de Empédocles en la obra de Nietzsche, véase mi Hölderlin y Nietzsche, dos paradigmas intempestivos de la modernidad en contacto, Sevilla: Reflexión, 1992. 
Ensayos de psicología contemporánea de Paul Bourget, lo cierto es que el modo en que él ha asumido la inevitabilidad del nihilismo, su inquietante duplicidad o la compleja dinámica de retorsión activa de sus efectos a adoptar por la propia propuesta transvaloradora, todo ello dibuja en su filosofía una estrategia teórica de inequívoco ascendente en la obra de los primeros románticos. Que, tal y como sugirió Ernst Behler, Nietzsche pudo haber estado familiarizado con esta cuestión y con el empleo específico de la noción de nihilismo en dicho contexto a través de la recensión que Friedrich Schlegel hizo de la obra de Jacobi, no es aquí lo decisivo ${ }^{24}$. Más importante resulta el hecho de que en Schlegel, como también en otros autores coetáneos, el asunto que con ése y otros rótulos se está dirimiendo aparece ya en su faz bifronte y suscita por ello la necesidad de arbitrar un estilo de pensamiento alternativo a las fórmulas dualistas de la filosofía precedente. Aquí radica el verdadero punto de contacto entre Nietzsche y los pensadores del naciente Idealismo y la Frühromantik: en un intento de superación de la escisión metafísica entre los dos mundos, que se concreta en una búsqueda de la desconocida raíz común de sensibilidad e intelecto; en una crítica al primado de la conciencia y en su remisión a un ser prerreflexivo, del que jamás puede dar cuenta plenamente el estilo discursivo de una racionalidad científico-instrumental, fijada a la estructura sujeto-objeto; en una voluntad de remontar el curso declinante de una ilustración insatisfactoria, debido a su restrictiva forma de concebir una humanidad íntegra y reconciliada consigo misma y con el mundo.

A la luz de esta relación, el proceso de maduración y despliegue de la filosofía nietzscheana adquiere una especial densidad y riqueza de contrastes. Todo cuanto Nietzsche pone en cuestión con su despiadada crítica de la cultura moderna no es sino la unilateralidad de las falsas vías de reconciliación arbitradas por las dos grandes tendencias decadentes de su tiempo: tanto la superficialidad del culto optimista a la razón y al progreso, cuanto el oscurantismo de la pura redención estética en una esfera superior y separada por completo de la prosaica vida cotidiana. Evidentemente, esto no significa que Nietzsche no haya sucumbido a esos extremos en algunas de sus formulaciones. El Ensayo de autocrítica de 1886 constituye un reconocimiento expreso de los equívocos

${ }^{23}$ SWB I 559 (Hiperión. Penúltima Versión).

${ }^{24}$ Cf. Behler, E., op. cit., p. 63. Behler remite a KA II 69. Para una aproximación a la génesis del nihilismo en el contexto del idealismo alemán, cf. Pöggeler, Otto, «Die Anfänge des Nihilismus-Diskussion», en Arendt, D., Der Nihilismus als Phänomen der Geistesgeschichte in der wissenschaftlichen Discusión unseres Jahrhunderts, Darmstadt: Wissenschaftliche Buchgesellschaft, 1974, pp. 304-349 (tr. J.A. Marín Casanova, en Barrios, A. (ed.), Pensar (en) el nihilismo, Reflexión, revista de filosofía, 2 (1996), pp. 15-50. Pöggeler hace notar que el término se encuentra, antes de la Carta a Fichte de Jacobi, en el libro de Daniel Jenisch, Sobre el fundamento y el valor de los descubrimientos del Señor Profesor Kant en la metafísica, la moral y la estética (Berlín: Viewek, 1796), asociado al ateísmo y al idealismo; y que F. Schlegel lo emplea ya en 1797 («Toda broma tiende al nihilismo (Voltaire, Swift)», aunque en un sentido distinto al de su identificación posterior del nihilismo con «la forma oriental-mística 
románticos de su primer libro (aunque, como ya he mostrado en otro lugar, ni siquiera a propósito de El nacimiento de la tragedia pueda decirse, en sentido estricto, que Nietzsche se haya limitado a sustituir la metafísica racionalista por esa cabal inversión del platonismo que acabaría siendo para él la concepción schopenhaueriana del mundo como voluntad y representación $)^{25}$. No obstante, en general, ocurre más bien lo contrario: las paradojas e incluso contradicciones del discurso nietzscheano proceden precisamente de su afán por mantenerse en un difícil equilibrio entre las distintas orientaciones degenerativas de la modernidad, que amenazan con retrotraerla a las viejas usanzas metafísicas. Nietzsche, por ejemplo, se ha desmarcado bien pronto de las jubilosas expectativas de ilustración popular que anidaban en el programa de una mitología de la razón, y ello con un claro coste para su pensamiento político-cultural, que a menudo ha visto desdibujada así la eficacia de sus denuncias de la nivelación por abajo y la mediocridad educativas de su tiempo. Pero no cabe duda de que este abandono del mesianismo revolucionario de aquellas proclamas le ha servido, por otro lado, para procurar corregir los residuos metafísicos presentes en ellas, en su estricta dimensión de metanarrativas. De hecho, tal vez este aspecto podría explicar por qué Nietzsche, tras su distanciamiento del romanticismo decadente de sus maestros, no ha querido hacer más explícitos sus vínculos con el primer romanticismo. Se entrecruzan aquí, en efecto, elementos de una y otra esfera de influencias. El joven Nietzsche se siente próximo a Schopenhauer allí donde éste le sirve para demoler la confianza racionalista -'socrática', la llama él- en que es posible «corregir el ser» (KSA I 99), confianza que aún alberga la joven generación idealista. En cambio, no sigue al filósofo de Danzig en su pretensión inversa de anular el ser una vez reconocida su intrínseca perversidad, incurabilidad y sinsentido; sino que se orienta hacia una afirmación de este fondo prerracional de la existencia, que conecta más bien con el talante de los primeros románticos. Así ha de entenderse ya la manera en que el joven Nietzsche habla del «enigmático Uno-primordial»: al situarlo en un nivel previo a los ámbitos de la voluntad y la representación, gozando estéticamente de su contradicción y desgarro en el plano de la disolución dionisíaca del principium individuationis o encubriéndolos en el plano de las bellas apariencias apolíneas, Nietzsche tiende a coordinar estos dos instintos artísticos, transposición de impulsos primordiales de la naturaleza, antes que a someterlos a una rígida jerarquía vertical de corte platónico. Como los primeros románticos, reclama la fuerza mitopoiética del logos para leer en el inagotable libro de la naturaleza esos otros signos que la ciencia moderna ignora. Pero esa otra dimensión de lo real no se capta propiamente mediante una simple mirada al pasado o una mera vuelta atrás, sino a través de una rememoración de la común instancia originaria de donde surgen mito y razón. En ese sentido, ya el trabajo de desmontaje del

del panteísmo» (KA XVIII: Philosophische Lehrjahre, 1 (1963), pp. 27; 573, 575).

Estudios Nietzsche, 5 (2005), ISSN: 1578-6676, pp. 33-66 
edificio olímpico de la cultura apolínea de los griegos dispensa a Nietzsche la enseñanza de que su trasfondo también constituye a su vez un estrato en el que el impulso dionisíaco ha recibido una específica elaboración y configuración cultural. El joven Nietzsche oscila todavía en ocasiones a la hora de precisar el estatuto ontológico del mundo de la realidad dionisíaca. Pero una cosa está clara: desde su primer libro, la tópica caracterización del retorno romántico a la naturaleza como cumplimiento escatológico de un reencuentro armónico con la bella y apacible totalidad perdida de los orígenes resulta cuestionada por él, por constituir una de esas ficciones engañosas de la cultura moderna:

«Aquí hay que manifestar que esta armonía, más aún, unidad del ser humano con la naturaleza, contemplada con tanta nostalgia por los hombres modernos, para designar la cual Schiller puso en circulación el término técnico 'ingenuo', no es de ninguna manera un estado tan sencillo, evidente de suyo, inevitable, por así decirlo, con el que tuviéramos que tropezarnos en la puerta de toda cultura, cual si fuera un paraíso de la humanidad: esto sólo pudo creerlo una época que intentó imaginar que el Emilio de Rousseau era también un artista, y que se hacía la ilusión de haber encontrado en Homero ese Emilio artista, educado junto al corazón de la naturaleza. Allí donde tropezamos en el arte con lo 'ingenuo', hemos de reconocer el efecto supremo de la cultura apolínea: la cual siempre ha de derrocar primero un reino de Titanes y matar monstruos, y haber obtenido la victoria, por medio de enérgicas ficciones engañosas y de ilusiones placenteras, sobre la horrorosa profundidad de su consideración del mundo y sobre una capacidad de sufrimiento sumamente excitable» ${ }^{26}$.

Como hemos insinuado antes, que la evocación de una infancia del hombre en el mundo -de un estado de inocencia donde necesidades y capacidades se mantendrían en equilibrio- revista aires rousseaunianos en autores como Hölderlin, no es óbice para que el poeta piense la unidad originaria de todo cuanto vive como algo que únicamente se capta a través de una suerte de apelación transcendental -eso sería la actividad estética- al 'ámbito' de posibilidad -eso sería die Natur- a partir del cual hay yo y mundo, pero que no se da de modo fáctico ni se reconquista en un proceso con término fijo. Por eso escribe Hölderlin en otro fragmento de 1795 titulado Hermócrates a Céfalo: «¿Crees en serio, pues, que el ideal del saber podría aparecer expuesto en algún tiempo determinado, en algún sistema determinado [...]? ¿Crees incluso que este ideal ya se haya hecho efectivo ahora, y que a Júpiter Olímpico no le falte más que el pedestal? [...] Por el contrario, siempre pensé que el hombre requiere tanto para su saber como para su obrar de un progreso infinito, de un tiempo ilimitado, a fin de acercarse al ideal

${ }^{25}$ Cf. Barrios, M., Voluntad de lo trágico, en espec. cap. VI.

${ }^{26}$ KSA I 37 (tr. A. Sánchez Pascual, Madrid: Alianza, 1973, p. 54). En lo que sigue, salvo indicación expresa en sentido contrario, las traducciones de obras de Nietzsche empleadas son las de A. Sánchez Pascual para Alianza Editorial.

${ }^{27}$ SWB II 841. Cito por la traducción, aquí ligeramente modificada, de Felipe Martínez 
ilimitado; a la opinión de que la ciencia pudiera ser completada o incluso que lo fuera en un tiempo determinado la llamé quietismo científico ${ }^{27}$. La idea de una progresividad infinita, que cuestiona la posibilidad de una autofundación del sujeto en los términos propuestos por la filosofía precedente, se expresa también con asiduidad en los textos de los representantes del círculo de Jena. Novalis la bosqueja ya en sus Fichte-Studien de 1795/6 y, al poco tiempo, Friedrich Schlegel hará de ella una de las divisas fundamentales de su pensamiento ${ }^{28}$. Anticipando el talante del escepticismo nietzscheano, estos autores reformulan en clave positiva la aporética jacobiana respecto al conocimiento de lo incondicionado: el absoluto no se vislumbra sino en el intento siempre necesariamente fracasado de aprehenderlo. «El destino del hombre es el de conjugar lo infinito con lo finito. La plena coincidencia, sin embargo, es inalcanzable» (KSA XVI 22). La ironía es la respuesta de Schlegel a esta inexpresabilidad última del Todo. Por una parte, la actitud irónica subvierte el orden lógico convencional, revelando hasta qué punto estas formas de representación de la realidad inducen una visión limitada de la misma. Por otra, mediante el juego con nuevas configuraciones expresivas, sugiere una totalidad abierta de sentido.

Nietzsche va a potenciar esta desconfianza hacia las rutinas gramaticales y demás 'supersticiones de los lógicos', que tienden a hacer que tomemos nuestros conceptos y categorías por verdades eternas, inscritas en la esencia de las cosas. Destituye su artificiosidad en la medida en que trata de hacerse pasar por la única, genuina realidad. Mas una vez aceptada la imposibilidad de transcender la apariencia, dota al artificio de un valor hermenéutico, como tentativa de aproximación a un mundo nunca descifrable por entero. En ese sentido, podría decirse que su crítica de la metafísica recoge aspectos básicos del movimiento disolutivo-creativo que es característico del concepto schlegeliano de ironía ${ }^{29}$. Y no hay que olvidar, además, que el abandono definitivo de los parámetros de su metafísica de artista y el consiguiente cuestionamiento de la noción schopenhaueriana de Voluntad como presunto ser de lo real se producen a partir de una intensificación de su temprana crítica de la 'cosa en sí', que tiene a la base una serie de apreciaciones sobre la naturaleza retórica y metafórica de todo lenguaje de claro antecedente en las teorías lingüísticas

Marzoa en Hölderlin, Ensayos, Madrid: Hiperión, 1976, p. 21.

${ }^{28}$ Cf. Frank, Manfred, 'Unendliche Annäherung'. Die Anfänge der philosophischen Frühromantik, Frankfurt: Suhrkamp, 1997. Sobre la poesía progresiva y universal, véase el esclarecedor trabajo de Diego Sánchez Meca, «El ideal de la autoformación en el horizonte del infinito», en Metamorfosis y confines de la individualidad, Madrid: Tecnos, 1995, pp. 101-136.

${ }^{29}$ Cf. Behler, E., «Nietzsches Auffassung der Ironie», Nietzsche-Studien, 4 (1975), pp. 1-35. Junto al ensayo Sobre la incomprensibilidad resulta particularmente pregnante a este respecto la caracterización schlegeliana de la ironía como constante alternancia de autocreación y autoaniquilación (KA II 15).

${ }^{30}$ La obra de Gerber, Gustav, Die Sprache als Kunst (Bromberg: Mittler, 1871-2) es aquí la principal influencia. Cf. Meijers, Anthonie, «Gustav Gerber und Friedrich Nietzsche. Zum 
del primer romanticismo, teorías según las cuales la poesía, en cuanto logos originario, alberga una expresividad superior a la del concepto ${ }^{30}$. Recordemos la afirmación de Friedrich Schlegel: «Pues éste es el principio de toda poesía: anular el curso y las leyes de la razón pensante-razonante y volver a ponernos en el bello desorden de la fantasía, en el caos originario de la naturaleza humana, para el que no conozco hasta ahora ningún símbolo más bello que el hormigueo multicolor de los antiguos dioses $»^{31}$.

Sin necesidad de caer en el error de frühromantizar a Nietzsche, es incuestionable, por lo tanto, el rendimiento exegético que ofrece una lectura de sus textos a partir de estas coordenadas. Así ocurre de modo destacado en el caso de sus referencias a la naturaleza como caos. En vez de tomar directamente esta designación a modo de una tesis metafísica en la estela de las de Schopenhauer, es posible reconocer en cambio su carácter eminentemente polémico, carácter que halla en el aforismo 109 de La gaya ciencia una de sus expresiones más depuradas: «Guardémonos de creer que el mundo es un ser viviente. ¿Hacia dónde se expandiría? ¿De qué se alimentaría? ¿Cómo podría crecer y reproducirse? ¿Sabemos aproximadamente qué es lo orgánico?: y a eso indeciblemente derivado, tardío, raro y contingente que percibimos solamente sobre la costa de la tierra, ¿deberíamos proclamarlo lo esencial, universal, eterno, como hacen quienes llaman al Todo un organismo? Esto me repugna. Guardémonos de creer si quiera que el Todo es una máquina; seguro que no está construido con una finalidad y le concedemos un valor demasiado elevado al emplear la palabra 'máquina'. [...] El carácter del mundo es, en cambio, caos por toda la eternidad, no en el sentido de una carencia de necesidad, sino en el de falta de orden, de estructuración, de forma, belleza, de sabiduría y como quiera que se denominen nuestras peculiaridades estéticas humanas. [...] Pero ¿¿cómo podríamos censurar o elogiar al Todo?; Guardémonos de achacarle crueldad o irracionalidad, o bien sus contrarios. ¡No le afectan en absoluto ninguno de nuestros juicios estéticos y morales! No tiene tampoco instinto de conservación, ni en general, instinto alguno; ni sabe tampoco de ninguna ley. Guardémonos de afirmar que hay leyes en la Naturaleza. [...] Pero i¿cuándo llegaremos al término de nuestro cuidado y nuestra precaución?! ¿Cuándo dejarán de oscurecernos todas esas sombras de Dios? i¿Cuándo habremos desdivinizado por completo a la Naturaleza?! i¿Cuándo podremos comenzar nosotros, los hombres, a naturalizarnos con la pura, redescubierta, redimida Naturaleza?! $\gg^{32}$

Al igual que ocurre en el texto nietzscheano, el caos del que hablan los pri-

historischen Hintergrund der sprachphilosophischen Auffassungen des frühen Nietzsche», Nietzsche-Studien, 17 (1988), pp. 369-390. Vid. también el artículo de Behler, «La teoría del lenguaje del primer romanticismo alemán y su repercusión en Nietzsche y Foucault', publicado en este mismo número de Estudios-Nietzsche, y el cap. 10 del minucioso libro de Santiago Guervós, Luis E. de, Arte y poder. Aproximación a la estética de Nietzsche, Madrid: Trotta, 2003, en espec. pp. 393ss.

${ }^{31}$ KA II 319 (tr. cast., p. 123.

${ }^{32}$ KSA III 467-9. La gaya ciencia, tr C. Crego y G. Groot, Madrid: Akal, 1982, pp. 147-9, 
meros románticos se define como tal por oposición a la interpretación unilateral de un cosmos ordenado de signo racionalista, que lo concibe como producto de un designio consciente o, al menos, orientado por un curso regular, susceptible de determinación unívoca. Lo que intentan propiamente los pensadores del primer romanticismo es activar de este modo una concepción capaz de conjugar orden y caos en el mundo sin resolverlos en una conciliación definitiva, antes bien, comprendiendo desde su tensión y entrecruzamiento la constante reinvención de lo real. Es en concreto el propósito schlegeliano de «dar forma y dirección al caos vacío» (KSA V 9) lo que parece resonar en el concepto de Bildung que Nietzsche expone en su escrito Sobre la utilidad e inconvenientes de la historia para la vida cuando, invocando una vez más a los griegos, afirma: «Nunca vivieron en orgullosa inaccesibilidad; su formación fue durante largo tiempo un caos de formas y conceptos extranjeros [...]. Sin embargo, la cultura helénica no se convirtió en un agregado gracias a aquella exhortación apolínea. Aprendieron los griegos gradualmente a organizar el caos» ${ }^{33}$. Más tarde, Nietzsche modulará el vitalismo de su segunda Intempestiva con una mayor adhesión al 'sentido histórico', cuestionará un modelo pedagógico de armonía entre interior y exterior demasiado prendido aún de las expectativas utópicas del humanismo, pero continuará fiel a su idea de que la cultura ha de ser «una physis nueva y perfeccionada» (KSA I 334), desarrollando la imagen del caos de fuerzas e impulsos antagónicos como contrafigura polémica de esa visión edulcorada de una naturaleza benigna, a la que bastaría con dejar a su libre despliegue para que educase nuestra sensibilidad. El de Nietzsche es, en ese sentido, un 'clasicismo superior', que procura no engañarse con sofisticadas idealizaciones y presupuestos metafísicos, reconociendo el coste que implica la ambición del gran estilo: «dominar el caos que se es; obligar al propio caos a hacerse forma, hacerse necesidad en la forma, hacerse lógico, simple, inequívoco, matemático, hacerse ley -; ésta es la gran ambición» (KSA XIII 246).

Ley, forma, orden no son, por tanto, constitutivos esenciales del universo, que hagan del azar, el desorden o la aleatoriedad de los procesos físicos meras apariencias. «Nosotros somos los únicos que hemos inventado las causas, la sucesión, la reciprocidad, la relatividad, la coacción, el número, la ley, la libertad, el motivo, la finalidad; y siempre que a este mundo de signos lo introducimos ficticiamente y lo entremezclamos como si fuera un 'en sí' de las cosas, continuamos actuando de igual manera que hemos actuado siempre, a saber, de manera mitológica» (MBM: KSA V 36). Una lectura parcial de este tipo de declaraciones nietzscheanas tiende siempre a ver en ellas una pura y dura revocación de todo valor de verdad y, consiguientemente, un abandono irracionalista a la más absoluta arbitrariedad. Lo cierto es que, salvo a modo de provocación ocasional o de explicación de cómo entra el nihilismo en el viejo

aquí ligeramente modificada. 
santuario de las verdades eternas, Nietzsche no sugiere semejante camino. Lo que propone es la modestia de quien reconoce que las nuestras son «verdades de poca apariencia» (HH: KSA III 25), esto es, interpretaciones perspectivísticas del modo en que nos va siendo dada la experiencia del mundo. El arranque de este planteamiento, tal como se expresa en el ensayo Sobre verdad y mentira en sentido extramoral, es, una vez más, la problematización de nuestra posibilidad de conocimiento de un 'mundo verdadero', heredada del kantismo. Y, en verdad, Nietzsche dramatiza ahí su argumentación en numerosos pasajes, recordando la manera en que Jacobi equiparaba el hecho de que nuestros razonamientos se hallen sometidos a una cadena de argumentos condicionados entre sí al hundimiento en un inesencial mundo aparente:

«¿Qué es para nosotros, en suma, una ley de la naturaleza? No nos es conocida en sí, sino solamente en sus efectos, es decir, en sus relaciones con otras leyes de la naturaleza que, a su vez, sólo nos son conocidas como relaciones. Por consiguiente, todas estas relaciones no hacen más que remitirse continuamente una a otras y, en su esencia, para nosotros son incomprensibles por completo; de ellas tan sólo conocemos en realidad lo que nosotros aportamos, el tiempo, el espacio, es decir, relaciones de sucesión y números» ${ }^{34}$.

Sin embargo, según hemos indicado antes, la tesis de que el mundo empírico es un mundo antropomórfico -debido a que nuestra percepción del mismo supone ya una transposición metafórica a otra esfera de significación, donde los datos resultan reelaborados a base de practicar asimilaciones e igualaciones de lo no-igual- no supone en absoluto para Nietzsche una destitución de lo sensible, sino precisamente lo contrario. Como ya anotara Hölderlin en su resumen de las Cartas sobre la doctrina de Spinoza, ahí donde Jacobi habla de 'ilusión', es necesario corregirlo y escribir 'fenómeno' (SWB I 827), recuperando la importante distinción kantiana entre Schein y Erscheinung. Hölderlin y el primer romanticismo reformulan este aspecto del criticismo, conjugándolo con la atmósfera spinozista del momento en busca de una afirmación incondicional del único mundo existente. Nietzsche lo hará de forma más drástica, procurando no recaer en presuposiciones idealizantes. Su crítica del mecanicismo y del determinismo se inscribe así dentro de esta estrategia teórica, pero no pretende ninguna liquidación de la ciencia.

Ha sido precisamente con objeto de desmarcar a Nietzsche de toda salida esteticista por lo que Maurizio Ferraris ha insistido en la coincidencia de sus planteamientos con los de autores leídos por él como Friedrich Albert Lange, Afrikan Spir o Gustav Teichmüller, inscritos en la corriente neokantiana y positivista de la segunda mitad del siglo XIX ${ }^{35}$. Es cierto que, en relación con la formación científico-natural de Nietzsche, ha seguido vigente durante

${ }^{33}$ KSA I 333 (tr. J.B. Llinares en Nietzsche, F., Antología, Barcelona: Península, 1988, p. 113).

${ }^{34}$ KSA I 885 (Antología, p. 48). 
demasiado tiempo un prejuicio similar al que, alimentado por los panfletos de Wilamowitz, le negaba un conocimiento profundo de los avances de la disciplina en su época, cuando, en realidad, su interés por las ciencias naturales no hizo sino incrementarse a partir de la década de 1870. De hecho, la misma insistencia en la categoría de relación del pasaje antes citado de Sobre verdady mentira es un claro reflejo de una concepción del conocimiento científico de las leyes naturales muy característica del paradigma vigente en aquel momento ${ }^{36}$. Ahora bien, para corregir los excesos de la sola lectura romántico-vitalista de la filosofía nietzscheana tampoco es necesario caer en los excesos contrarios, como tiende a hacer Ferraris. La referencia a Lange puede servir para aclarar y completar el significado de algunos aspectos del ficcionalismo nietzscheano; pero no para minimizar y reemplazar en su obra el influjo de la Frühromantik, en cuyo nihilismo poético ha encontrado Nietzsche por primera vez una lectura positiva de la experiencia disolutiva del mundo verdadero, que ha sabido tomarla como ocasión para una afirmación del 'sentido de la tierra', liberando su ilimitado potencial de recreación, reprimido por la metafísica. Una vez más, lo distintivo del pensamiento nietzscheano es aquí su original engarce de elementos, en este caso, podríamos decir, de 'estética' y 'fisiología'. Nietzsche no reniega del testimonio de los sentidos, ciertamente. Para él, por ejemplo, resulta fundamental partir del cuerpo y utilizarlo como hilo conductor, por cuanto constituye el fenómeno más rico de conexión con el mundo, el que nos permite una aproximación más diversificada e intensa a su permanente dinamismo. Pero sí que subraya la circunstancia de que, ya al nivel de las sensaciones, actúa en nosotros un impulso metafórico de asimilación de diferencias que, igualando nuestra percepción de aconteceres distintos y haciéndolos comparables entre sí, implica cierto falseamiento (en otras ocasiones, de forma menos provocativa, Nietzsche dirá: una interpretación) de lo dado, sólo en virtud del cual nos resulta viable el conocimiento de un mundo de regularidades manejable y previsible. Conocer es, pues, aplicar esquemas de identidad a la multiplicidad del devenir ${ }^{37}$. Ahora bien, hay que insistir en este punto: ni Nietzsche ni los primeros románticos extraen de este legado kantiano una impugnación del conocimiento. La fuerza inventiva no es considerada como un obstáculo, sino como condición posibilitante del trabajo de la 'razón'. Todo logos, todo lenguaje, la lógica misma, se desarrollan a partir de la suposición de que hay casos idénticos, suposición surgida a partir de requerimientos vitales y necesidades de orientación en el mundo. Por eso afirma Nietzsche que el mundo es lógico

${ }^{35}$ Ferraris, Maurizio, Nietzsche y el nihilismo, Madrid: Akal, 2000.

${ }^{36}$ Cf. Kaulbach, Friedrich, «Nietzsches Interpretation der Natur», Nietzsche-Studien, 10/11 (1981/82), p. 445.

${ }^{37}$ Es también en este sentido en el que, como ya he comentado en alguna otra ocasión, hay una dimensión de 'platonismo insuperable' en Nietzsche; puesto que conocer es, en efecto, 
en la medida en que nosotros lo hemos logicizado y que necesitamos de esta ficción útil para poder vivir.

Este planteamiento puede considerarse próximo al de pensadores como Lange. Sin embargo, en opinión del propio Nietzsche, se aparta de forma notable de ese «canon de verdad del sensualismo», característico de «obreros de la fisiología» (JGB: KSA V 37), «filosofastros de la realidad» (ibid. 23) y otros promulgadores coetáneos de un universo concebido al gusto de la «estirpe ruda y laboriosa de maquinistas» (ibid. 29) que parece gobernar el mundo moderno. Desde luego, no supone para Nietzsche el punto de vista dominante en su época. Él lo señala expresamente cuando escribe: «Acaso sean cinco o seis las cabezas en las cuales va abriéndose paso ahora la idea de que también la física no es más que una interpretación y un arreglo del mundo (¡según nosotros!, dicho sea con permiso), y no una aclaración del mundo» (ibid. 28). En esencia, pues, Nietzsche sigue viendo en la mentalidad positivista de su tiempo otra modalidad más de creencia en un mundo 'verdadero-en-sí', que se resiste aún a aceptar que nuestros modelos de descripción de la realidad son justamente eso, modelados y construcciones filtrados por categorías humanas. Por eso, frente a quienes sólo conceden crédito, de forma dogmática, a la apariencia visible, Nietzsche se sitúa al lado de «esos actuales escépticos, anti-realistas y microscopistas del conocimiento, cuyo instinto les lleva a alejarse de la realidad moderna» (ibid. 24) ¿Qué quiere decir con esto? Ante todo, una vez más, que en la naturaleza no hay orden, armonía ni regularidad, en el sentido en que solemos atribuírselos, proyectando en ella nuestros valores, como ocurre en el caso de la idea moderna de igualdad ante la ley: «Perdóneseme el que yo, como viejo filólogo que no puede dejar su malicia, señale con el dedo las malas artes de la interpretación: pero es que esa 'regularidad de la naturaleza' de que vosotros los físicos habláis con tanto orgullo, como si - - no existe más que gracias a vuestra interpretación y a vuestra mala 'filología' , - ¡ella no es una realidad de hecho, no es un 'texto', antes bien es tan sólo un arreglo y una distorsión ingenuamente humanitarios del sentido, con los que complacéis bastante a los instintos democráticos del alma moderna!» (ibid. 37).

Las malas artes del humanismo metafísico no han dejado de promover esta ilusión naturalista a lo largo de la historia de la cultura occidental, permitiéndonos leer en la naturaleza el canon de nuestras propias leyes y exigencias. En el apartado primero de Más allá del bien y del mal, dedicado a los prejuicios de los filósofos, Nietzsche analiza detenidamente las diversas formas de este autoengaño, del precepto estoico de vivir según la naturaleza al 'cretinismo

recordar, o sea, interpretar como ya visto lo nuevo que aparece.

${ }^{38}$ Cf. respectivamente los aforismos noveno y vigésimo primero. Sobre la ciencia como prejuicio, véase también el aforismo 373 de La gaya ciencia, en el que Nietzsche cuestiona «la creencia de los naturalistas materialistas en un 'mundo de la verdad', que sería posible abordar con nuestra pequeña y cuadriculada razón humana», defiende el carácter ambiguo de 
mecanicista' de los investigadores de la naturaleza y de quienes, como ellos, «naturalizan hoy en el pensar» ${ }^{38}$. De su análisis se deduce que la ciencia del momento, imbuida aún de determinismo y de fe objetivista en la verdad incondicional, así como de una visión optimista y lineal del progreso histórico, se encuentra también en serio peligro de sucumbir al nihilismo decadente, tan pronto como queden al descubierto sus más profundos presupuestos, entre ellos, el afán de dominio e instrumentalización que se aloja tras la aséptica voluntad de verdad del teórico o los prejuicios sensoriales y psicológicos de su fe en un mundo del ente:

«Sujeto, objeto, un hacedor correspondiente al hacer: no olvidemos que todo esto designa una mera semiótica y no designa nada real. La mecánica en cuanto teoría del movimiento es ya una traducción al lenguaje sensorial del hombre. Tenemos necesidad de unidades a fin de poder calcular: no se ha de asumir por ello que tales unidades existan: Hemos derivado nuestro concepto de unidad de nuestro concepto de 'yo' -nuestro artículo de fe más antiguo. Si no nos concibiéramos como unidades no habríamos formado jamás el concepto de 'cosa'. Ahora, bastante tarde, estamos sobradamente convencidos de que nuestra concepción del concepto ‘yo' no ofrece ninguna garantía de una unidad real. A fin de preservar teóricamente la concepción mecánica del mundo hemos de hacer la salvedad de hasta qué punto lo llevamos adelante mediante dos ficciones: con el concepto de movimiento (extraído de nuestro lenguaje sensorial) y con el concepto de átomo = unidad (proveniente de nuestra 'experiencia' psíquica)» ${ }^{39}$.

Ahora bien, tal y como se desprende del pasaje citado, si Nietzsche extrema su crítica de los prejuicios en que se sustenta toda fe en la razón, no es para desechar ésta ni para proponer una absoluta revocación de los mismos, sino más bien para aprender a aceptar en su justa medida la inevitabilidad de la instancia pre-judicial de nuestras verdades. No cabe, por ejemplo, prescindir enteramente de la ficción de cosas en movimiento, que es la que nos permite una explicación científica del mundo. Lo cuestionado por Nietzsche no es el empleo de estas unidades, sino el grosero fetichismo con que las asume una

la existencia y concluye: «una interpretación que no admita más que contar, calcular, pesar, ver y prender es una torpeza y una ingenuidad, a menos que sea enfermedad mental, idiotismo. ¿No es, por el contrario, harto probable que precisamente lo más superficial y externo de la existencia -lo que tiene de más aparente, su piel, su materialización- sea lo que puede asirse en primer lugar? ¿o quizás incluso lo único que puede asirse? Una interpretación 'científica' del mundo, tal como vosotros la entendéis bien podrá ser, pues, una de las más estúpidas, esto es, una de las sensualmente más pobres de todas las interpretaciones posibles del mundo: les digo esto al oído y al conciencia a los señores mecanicistas, a los que hoy día les gusta mezclarse con los filósofos y que en general creen que la mecánica es la doctrina de las leyes primarias y últimas sobre cuyo fundamento tendría que levantarse toda la existencia» (KSA III 625-626; ed. cast., p. 302).

${ }^{39}$ KSA XIII 258: 14[79], de primavera de 1888, encabezado por la anotación «Voluntad de 
concepción como la mecanicista, que de esa manera practica una excesiva homogeneización e indiferenciación (adiaphoria) de la dinámica del devenir. Así pues, cuando el fragmento prosigue con la consideración de una hipótesis alternativa -la de la voluntad de poder como quanta dinámicos de fuerza, cuya esencia no consiste sino en su relación de tensión con otros quanta, sin ninguna unidad subyacente al proceso- no es porque Nietzsche pretenda transcender de ese modo la fenomenalidad de la concepción mecanicista, sino porque aspira a reducir, en la medida de lo posible, la rigidez de las abstracciones con las que opera dicha concepción. Ese es el sentido de la tentativa nietzscheana, tan malinterpretada por Heidegger, de «imprimir al devenir el carácter del ser» (KSA XII 312): no el de atribuir al devenir un carácter estable, determinado como su ser más propio; sino el de tensar y dinamizar nuestro pensamiento al máximo permitido por sus constricciones lógico-lingüísticas. Sigue tratándose, pues, de una faceta más de la actividad crítico-disolutiva suscitada por la genealogía de nuestras representaciones metafísicas.

La investigación genealógica señala el punto ciego más allá del cual no puede ir la razón en su deseo de autofundación: ésta no ha de llegar, por ejemplo, al extremo de considerar ese mundo propio que el hombre ha puesto junto al otro mediante el lenguaje como si se tratase de un mundo aparte y autosubsistente de verdades eternas. La reificación de los procesos de racionalización de nuestra experiencia dio lugar a la creencia en un mundo ideal, radicalmente distinto al mundo sensible, no sometido como éste al cambio, la corrupción y la muerte: una creencia que acabó por depreciar lo existente, cuando el platonismo dotó de sustento teórico al anhelo cristiano de redención del alma en un más allá. Este anhelo de retorno del alma a su genuina morada, a un ámbito del puro ser, separado de la apariencia y el no-ser, ha seguido operando, según Nietzsche, incluso ahí donde la fe religiosa tradicional había comenzado hace tiempo a declinar. Es el caso de la visión racionalista de un mundo ordenado y regulado por estrictos patrones lógico-matemáticos; pero también el de la visión sublimada de una naturaleza idílica, desprovista de toda negatividad. El retorno rousseauniano a la naturaleza ${ }^{40}$ le resulta así otra versión más de ese ideal metafísico de pureza incontaminada, incapaz de admitir cómo algo puede surgir de su contrario, por ejemplo, lo racional de lo irracional, el altruismo del egoísmo o la verdad de los errores. Dicha incapacidad es lo que Nietzsche combate en todos los casos, y para ello recurre, como estamos viendo, a la idea del caos como rostro jánico de una naturaleza terrible y seductora a un tiempo,

poder - Filosofía - Quanta de poder. Crítica del mecanicismo» (Antología, p. 170).

${ }^{40}$ En Crepúsculo de los ídolos, Rousseau figura entre los 'imposibles' de Nietzsche por su «retorno a la naturaleza in impuris naturalibus» (KSA VI 111). En los fragmentos póstumos son frecuentes las invectivas contra el pensador ginebrino, contrapuesto a menudo a Voltaire, por su sentimentalización y moralización de la naturaleza (Cf. v.g. los fragmentos KSA XII: 9[125], 9[146] y 9[184], de otoño de 1887). En ese sentido, Nietzsche lo considera un antecedente del romanticismo, "en el que confluyen los ideales cristianos y los de Rousseau, con una cierta 
imposible de quedar fijada bajo una única imagen si no es a sabiendas de la interpretación que de ese modo se añade al texto.

El papel que juegan, por tanto, en el pensamiento nietzscheano todas esas menciones del trasfondo caótico de la existencia resulta muy similar al de ese otro elemento recibido del contexto de la Frühromantik que es la ironía schlegeliana. Ya Walter Benjamin supo ver en esa técnica de ironización o reflexión infinita el motivo teórico fundamental que une a Nietzsche con los primeros románticos ${ }^{41}$. En efecto: el caos, tema nunca expreso que permite que haya variaciones, funciona aquí como factor de extrañamiento frente a todos los intentos de leer directamente y de una vez por todas el texto de lo real. El heraclitismo de Nietzsche, su convicción más íntima de que el devenir resulta un juego de fuerzas inasible, le lleva a ir extremando cada vez más las cautelas de su escritura filosófica, a fin de que ésta no quede atrapada en las redes de la gramática ontoteológica. El pathos de la verdad del filósofo ha de ir aprendiendo a convivir con la buena voluntad de la apariencia del arte trágico-dionisíaco hasta llegar a cultivar un nuevo estilo, un buen gusto postmetafísico, según pone de manifiesto el prefacio a la segunda edición de La gaya ciencia: «No, ese mal gusto, esa voluntad de verdad, de 'verdad a toda costa' la hemos perdido [...]. Ya no creemos que la verdad siga siéndolo si se le arrancan los velos: hemos vivido demasiado como para creérnoslo [...] Se debería tener en más alta estima el pudor con el que la Naturaleza se ha ocultado tras enigmas e incertidumbres variopintas. ¿Acaso es la verdad una mujer que tiene razones para no dejar ver sus razones?»(KSA III 352). En uno de los pasajes más crípticos de su proyecto de composición de un drama titulado Empédocles (iniciado a finales de 1870 y abandonado en 1872), en el que la figura del pensador agrigentino, prototipo del futuro personaje de Zaratustra, encarna la crisis de su juvenil metafísica del pesimismo, Nietzsche había dejado escrito también: «La mujer como naturaleza» (KSA VII 126). Caos, mujer, naturaleza: reversos de la razón. Ariadna como laberinto de Dionisos. La invocación de esa extrañeza que perturba a la palabra común, demasiado lenta para captar los matices diferenciales y la profundidad de la superficie, de los pliegues y las formas de este mundo apariencial, es el legado esencial de los primeros románticos a Nietzsche. Resulta decisivo comprender este punto, porque es el que aleja de forma más nítida al pensamiento nietzscheano de los residuos metafísico-románticos, schopenhaueriano-wagnerianos, de juventud. En su obra de madurez, Nietzsche no sostiene la tesis de que el mundo verdadero es una Voluntad irracional y la razón una falsa apariencia que debemos obviar, ya sea para fundirnos extáticamente en el torrente impetuoso de la vida o para renunciar ascéticamente a todo deseo de perseverar en la existencia. Tampoco en este

nostalgia del tiempo antiguo de la civilización pseudoaristocrática'.

${ }^{41}$ Benjamin, Walter, Der Begriff der Kunstkritik in der deutschen Romantik (1919), en Gesammelte Schriften. ed. R. Tiedemann y H. Schweppenhäuser, Frankfurt: Suhrkamp, 1980, 
sentido irracionalista preconiza ninguna suerte de retorno al Caos primigenio. Caos es el término que emplea para expresar la inocencia del devenir, esto es, la imposibilidad de imputarle al mundo la responsabilidad de una orientación definida de acuerdo a nuestras estimaciones de valor. Si sus textos suelen incidir en el reverso sombrío de esta imagen cósmica, es sobre todo por su valor como instrumento de crítica al optimismo racionalista, siendo éste el punto que más lo aproxima en su primer libro a la atmósfera romántica de Schopenhauer y Wagner. Sin embargo, la oposición a toda suerte de teleología y de imposición de una determinación constante a lo real también acaba por involucrar en su obra de madurez a la metafísica negativa del romanticismo. Ésta no promueve sino una especie de 'rousseaunianismo invertido', que experimenta el mundo como un sinsentido insoportable, del que habría que tratar de escapar del modo más rápido posible. Nietzsche comprende al fin que estas posiciones no hacen más que invertir la jerarquía platónico-cristiana, conservando el mismo estilo metafísico de juzgar y condenar la existencia: «Partiendo de estados en que experimentamos el mundo como demasiado absurdo, malo, pobre, engañoso como para suponer o desear aún que el ideal se halle en él, se lleva a cabo la proyección del ideal en lo antinatural, antirreal, antilógico. El estado del que así juzga es el de 'empobrecimiento' del mundo como consecuencia de su sufrimiento» (KSA XIII 64). Su error de juventud consistió en dejarse seducir por esta hipostatización del momento negativo de la crítica romántica. Al percatarse de la finalidad reactiva de ese desprecio del mundo que dejan traslucir las consideraciones de Schopenhauer acerca de los males y miserias de la existencia, o de la función narcotizante y mixtificadora del arte wagneriano, Nietzsche desenmascara su pertenencia a la misma lógica decadente del platonismo. El «usual finale de los románticos»-escribe en su Ensayo de autocrítica- es un final en la nada, un repudio del mundo y un retorno a la vieja fe, al viejo dios, bajo cualquiera de sus diversas expresiones, en definitiva, una vuelta al consuelo transmundano. El arte irónico del consuelo intramundano, que Nietzsche reclama en ese texto como antítesis de todo «consuelismo metafísico» (KSA I 22), se caracteriza en cambio por la afirmación incondicional de la vida. Incondicional, por cuanto no es susceptible de fundarse con firmeza trascendente en ninguna instancia de legitimación. Así, el desarrollo maduro y consecuente de la temprana crítica al concepto de cosa en sí da al traste con la aspiración del genio romántico de proclamarse portavoz del Ser o ventrílocuo de la divinidad. La experiencia artística no supone ya una superación del engaño de las apariencias propias de un mundo desdibujado por el principio de razón, ni un regreso al caos informe, una vez contemplada en su inmediatez la esencia más íntima de lo real. De hecho, lo que distingue ahora al artista decadente es, para Nietzsche, su incapacidad de sobreponerse al hondo desánimo vital que trasluce su visión negativa del mundo y, por tanto, para dar forma a ese caos. Por el contrario, Nietzsche entiende que una cultura trágica es aque- 
lla que se sobrepone a los aspectos duros, terribles y problemáticos que entraña la existencia, sin pretender disimularlos ni convertirlos en una objeción radical contra ella, y sin recurrir tampoco a la fe metafísica en otro mundo mejor o más verdadero, situado más allá. El pesimismo romántico es una consecuencia más de la quiebra de la vieja fe metafísica en un mundo ideal, incapaz de sobreponerse al estilo de valorar sustentado en dicha fe. Consciente de ello, Nietzsche se dispone a la búsqueda de un modo de expresión postmetafísico, donde salga a la luz el carácter interpretativo de nuestras propuestas de sentido y verdad. La concepción de la voluntad de poder se constituye explícitamente como un tipo de consideración de la apariencia que, al tiempo que la toma como «única y verdadera realidad de las cosas», «se resiste a su transformación en un imaginario mundo verdadero», precisamente porque reconoce que «a ella son aplicables todos los predicados, así como sus contrarios» (KSA XI 654). Imposible de definir en su «naturaleza proteiforme, inaprensible y fluida», Nietzsche ensaya una posible designación de este mundo «desde dentro» (ibid.), que siga siendo capaz de dar cuenta de la insalvable contradictoriedad de su devenir, que reconozca que «lo opuesto a este mundo fenoménico no es el 'mundo verdadero', sino el mundo informe-informulable del caos de sensaciones -así pues, otra modalidad del mundo fenoménico, 'incognoscible' para nosotros» (KSA XII 396). Por eso, no sólo insiste en que lo que Schopenhauer denominaba voluntad es algo incognoscible y que la voluntad de la que él habla únicamente como nombre posee unidad, sino también en que, dado que aquello que podemos expresar mediante el lenguaje es siempre 'una simple relación', no un 'ser en sí mismo', la noción de voluntad de poder no designa un sustrato permanente de los fenómenos y mucho menos una causa única del acontecer, sino que trata de expresar una dinámica relacional, que en nosotros se traduce como despliegue multiforme de fuerzas en conflicto. El único 'ser' del que tendría sentido hablar, escribe Nietzsche en un fragmento inédito de 1881, «es cambiante, no-idéntico a sí mismo, tiene relaciones» ${ }^{42}$.

Esto implica que la dilucidación del querer de la voluntad de poder, que algunos intérpretes tan destacados como Heidegger se empeñan en resolver en clave de recaída en la metafísica, no puede poseer más que el estatuto de una ficción

vol. I, pp. 7-122 (tr. J.F. Ivars y V. Jarque, Barcelona: Península, 1988).

${ }^{42}$ KSA IX 570: 11[130]. Véase también el 14[93], de primavera de 1888: «la 'apariencialidad' pertenece ella misma a la realidad: es una forma de su ser, i.e., en un mundo en el que no existe ser, ha de crearse primero por medio de la apariencia un cierto mundo predecible y calculable de casos idénticos [...]: abstracción hecha de nuestra condición de vivir en él, [...] no existe como mundo 'en sí', es esencialmente un mundo de relación [Relations-Welt]; tiene un rostro diferente desde cada punto, según las circunstancias; su ser es esencialmente distinto en cada punto» (KSA XIII 271).

${ }^{43}$ Resulta crucial atender en este punto a la retórica del texto nietzscheano, que una y otra vez insiste en el carácter hipotético de su formulación de la voluntad de poder. Así, en el aforismo 36 de Más allá del Bien y del mal: «Suponiendo que ninguna otra cosa esté 'dada' realmente 
regulativa, tal como Nietzsche declara de manera expresa en numerosas ocasiones $^{43}$. Cuando Heidegger se pregunta en su escrito La frase de Nietzsche «Dios ha muerto» qué entiende Nietzsche por vida («aquello en lo que reside la esencia determinante de todo lo vivo», precisa el de Messkirch), como cifra del nuevo valor supremo procurado por la transvaloración del nihilismo, dice plantear esta cuestión en un contexto donde el valor aparece ligado a la óptica perspectivística. Sin embargo, el perspectivismo nietzscheano se difumina bastante en esta lectura. $\mathrm{Al}$ comentar que con los valores en tanto que puntos de vista se establecen las condiciones de conservación y aumento y que, por consiguiente, conservación y aumento caracterizan los rasgos fundamentales de la vida, en tanto que copertenecientes, Heidegger tiende a conferirle a estas condiciones un estatuto de fijeza y estabilidad que no poseen en Nietzsche. Añade entonces una consideración, que aún parece bien nietzscheana: «Toda conservación de la vida se encuentra al servicio del aumento de la vida» ${ }^{44}$; y otra, que ya no lo es tanto: «Pero no es posible ningún aumento si no existe ya y se conserva un estado asegurado y sólo de ese modo capaz de aumento» ${ }^{45}$. Con esta segunda observación, Heidegger ha devuelto plenamente al circuito metafísico del aseguramiento y la consistencia del ser las nociones de vida y voluntad de poder pensadas por Nietzsche como derroche, virtud donadora y desbordamiento sin fondo ni reserva, haciéndolas recaer bajo el molde schopenhaueriano de la Voluntad que sólo quiere quererse y conservarse a sí misma. Mas, como decimos, Nietzsche explota la indescifrabilidad última de 'lo real' para dar a su nueva concepción del mundo el carácter de una interpretación que se sabe tal, que se guarda de atribuirse la prerrogativa de establecer una lectura unívoca del tejido infinito de la existencia. En el aforismo de Más allá del bien y del mal citado anteriormente, en el que se reprocha a los físicos su mala filología por tomar la 'regularidad de la naturaleza' como una realidad de hecho, una vez más, Nietzsche no contrapone a esa interpretación determinista la idea de voluntad de poder como verdadero texto de la naturaleza, sino cabalmente como otra interpretación: «y podría venir alguien que con una

más que nuestro mundo de apetitos y pasiones, suponiendo que nosotros no podamos descender o ascender a ninguna otra 'realidad' más que justo a la realidad de nuestros instintos -pues pensar es sólo un relacionarse esos instintos entre sí- ¿no está permitido hacer el intento y hacer la pregunta de si eso dado no basta para comprender también, partiendo de lo idéntico a ello, el denominado mundo mecánico (o material)?» (KSA V 54). Nietzsche insiste ahí: «tenemos que hacer el intento [Versuch] de considerar hipotéticamente... como dice mi tesis». Y en el fragmento 38[12], de junio-julio de 1885 («¿Y queréis saber qué es para mí ‘el mundo’? ¿He de mostrároslo en mi espejo?» KSA XI 610) acude una vez más a un motivo clásico del mito de Dioniso -quien al mirarse en un espejo ve reflejado un mundo- ya no para contraponer el carácter apariencial de este reflejo a su verdadera imagen, sino para subrayar tanto la condición interpretativa de $s u$ «mundo dionisíaco del crearse-a-sí-mismo eternamente, del destruirse-así-mismo eternamente, este mundo-misterio de los deleites dobles» (ibid.), cuanto su estricta atenencia al ámbito fenoménico.

${ }^{44}$ Heidegger, Martin, Holzwege, Frankfurt: Klostermann, 1950, p. 211 (tr. A. Leyte y H. Cortés, Madrid: Alianza, 1984, p. 207). 
intención y un arte interpretativo antitéticos supiese sacar de la lectura de esa misma naturaleza y en relación a los mismos fenómenos, cabalmente el triunfo tiránico, despiadado e inexorable de pretensiones de poder - un intérprete que os pusiese de tal modo ante los ojos la universalidad e incondicionalidad vigentes en toda 'voluntad de poder', que casi toda palabra, hasta la misma palabra 'tiranía', acabase pareciendo inutilizable o una metáfora debilitante y suavizadora -algo demasiado humano-; y que, sin embargo, afirmase acerca de este mundo, en fin de cuentas, lo mismo que vosotros afirmáis, a saber, que tiene un curso 'necesario' y 'calculable', pero no porque en él dominen leyes, sino porque faltan absolutamente las leyes y todo poder saca en cada instante su última consecuencia. Suponiendo que también esto sea nada más que interpretación - ¿y no os apresuraréis vosotros a hacer esa objeción? -bien, tanto mejor» (KSA V 37).

Así es como hay que entender también sus diferentes alusiones al «texto básico homo natura» que seguiría latiendo bajo las orgullosas palabras del humanismo moderno: «retraducir al hombre a la naturaleza» (ibid. 169) no posee entonces la significación de un rescate del origen inmaculado, opuesto a la falsa identidad racional, pues toda identidad, también la de la Naturaleza, es construida, ha devenido (así que no cabe apelar a presunta jerarquía natural alguna). Tiene más bien el sentido de un hacerse cargo del coste real que entraña el proceso de la cultura y de los riesgos que conlleva el olvido o la mixtificación de dicho proceso. De ahí que Nietzsche hable insistentemente de 'naturaleza' y 'natural' como productos, no del 'laisser aller' ni del fácil fluir de una disposición espontánea, sino de una coacción prolongada: «En contraposición al laisser aller [dejar ir], toda moral es una tiranía contra la 'naturaleza', también contra la 'razón': esto no constituye aún, sin embargo, una objeción contra ella, pues para eso habría que volver a decretar, sobre la base de alguna moral, que no está permitida ninguna especie de tiranía ni de sinrazón. Lo esencial e inestimable en toda moral consiste en que es una coacción prolongada» (ibid. 108). Dicha coacción la ejerce el hombre sobre la multiplicidad de fuerzas e impulsos que pugnan en él por expresarse e imponer su orientación. La unidad resultante de ese tenso equilibrio entre impulsos antagónicos lo es sólo como organización y estructura (KSA XII 104: 2[87]), no como sustancia. Sin embargo, el empeño en dar valor eterno, universal y absoluto a determinadas configuraciones humanas, resultado del trabajo cultural de milenios, ha distinguido a las religiones, morales y metafísicas del pasado. Nietzsche piensa que esta sobredeterminación ha sido enormemente perjudicial, porque ha ido desarrollando una actitud de sospecha y condena de los impulsos que estaban en el origen de aquellos valores considerados como superiores, a los cuales se ha querido emancipar de su procedencia para conferirles mayor dignidad y trascendencia, y, con ello, ha promovido el resentimiento contra la vida que se detecta en los fundamentos de nuestra cultura cristiano-burguesa. Con todo, él no sólo no propone vuelta alguna a un paganismo irrecuperable o a un dionisismo trasnochado, sino que 
curiosamente reconoce aspectos muy provechosos generados por este intenso sometimiento de los instintos: «La prolongada falta de libertad del espíritu, la desconfiada coacción en la comunicabilidad de los pensamientos, la disciplina que el pensador se imponía de pensar dentro de una regla eclesiástica o cortesana o bajo presupuestos aristotélicos, la prolongada voluntad espiritual de interpretar todo acontecimiento de acuerdo con un esquema cristiano de volver a descubrir y a justificar al Dios cristiano incluso en todo azar - todo ese esfuerzo, violento, arbitrario, duro, horrible, antirracional ha mostrado ser el medio a través del cual fueron desarrollándose en el espíritu europeo su fortaleza, su despiadada curiosidad y su sutil movilidad» (MBM: KSA V 109).

Este rigor ha educado el espíritu, admite Nietzsche ${ }^{46}$. Y es precisamente la aceptación de la evidencia de que toda cultura se basa en una tiranía y sometimiento de los instintos lo que le lleva a emplear términos tan crudos como los de doma y crianza -«realidades, dice, de las que el 'mejorador' típico, el sacerdote, nada sabe -nada quiere saber» (CI: KSA VI 99) - para expresar sus ideas en torno a la educación del hombre futuro. De ese modo pretende poner de relieve la circunstancia de que el proceso educativo implica siempre un debilitamiento de la impulsividad primera y descontrolada de los instintos, aunque también quiere con ello llamar la atención acerca del grave riesgo de que, al haber extremado dicho proceso, se haya podido echar a perder por entero esa «bestia enfermiza» (ibid.) que es siempre todo hombre cultivado. No existe aquí apostolado alguno de la fuerza bruta. Nietzsche insiste en la estupidez primeriza de las pasiones y en la necesidad de disciplinarlas y darles forma. Asumir que «la naturaleza no es moral», que la vida no es buena, ni noble, ni sagrada no significa en absoluto abandonarse a su despliegue irreflexivo. De lo que se trata es de contar con dicha dimensión de sinrazón y barbarie de nuestras pulsiones, a fin de, sin segarlas ni cortarlas de raíz, matizarlas, cultivarlas, embellecerlas y, con ello, ciertamente, domesticarlas. En suma, se trata de practicar ahora un «ascetismo irónico» (KSA XII 291). Ahora bien, por ese mismo motivo, Nietzsche se opone diametralmente al castradismo promovido por la moral cristiana, que ha atacado de manera directa a las pasiones y apetitos meramente para prevenir su estupidez, siendo en ese sentido en el que él se refiere a una «moral contranatura»: en la medida en que «atacar a las pasiones en su raíz significa atacar la vida en su raíz» (ibid. 83). Semejante extremismo le parece tanto o más bárbaro que su contrario y, por lo demás, bien sintomático, puesto que «los medios radicales tan sólo les resultan indispensables a los degenerados» (ibid).

En pos de una formulación no dualista de las relaciones entre instinto y

${ }^{45}$ Ibid.

${ }^{46}$ Por cierto que matizando en este punto la tesis de la legitimidad y autoafirmación de la modernidad defendida luego por pensadores como Hans Blumenberg, al señalar que el cultivo de la curiosidad teórica tiene una genealogía de más largo alcance y calado. Cf. el aforismo 188 
razón, Nietzsche habla entonces a este respecto de una «razón restablecida» (ibid. 89), donde el síntoma más claro de la salud del espíritu es su capacidad para acoger una multiplicidad pulsional y coordinarla, en lugar de quedar destruido por esa amalgama de fuerzas. Son estas modulaciones y gradaciones las que deciden las relaciones de salud y enfermedad que se dan en el seno de una cultura $^{47}$. Nietzsche no comparte el mito romántico del afuera, de la vuelta a una pureza absolutamente externa a la decadencia. «La naturalización del hombre en el siglo XIX -escribe en un fragmento póstumo de otoño de 1887- no es un 'regreso a la naturaleza', pues no ha habido nunca una humanidad natural. [...] El hombre llega a la naturaleza tras una larga lucha - nunca 'regresa'» (KSA XII 482). Si nuestra posición frente al conocimiento, la moral, el arte o la naturaleza se ha hecho 'más natural', ha sido sólo en la medida en que nos hemos ido distanciando de la 'desnaturalización' cristiana. «Esto -concluye Nietzsche- suena a ciertos oídos como si hubiera progresado la corrupción: y lo cierto es que el hombre no se ha acercado a la 'naturaleza' de la que habla Rousseau, sino que ha dado un paso más en la civilización que éste repudiaba» (ibid. 483-484). La 'naturalización', en definitiva, únicamente es pensable como 'retraducción', como traslado respecto de la posición 'desnaturalizada' precedente, cuya disolución (corrupción) comienza a hacerse cada vez más evidente. Retomando la manera en que ya Friedrich Schlegel había proyectado su idea del caos creador sobre el plano histórico, Nietzsche contempla entonces la situación de hibridación y mezcolanza propia de la cultura moderna no sólo como un signo de decaimiento y falta de originalidad, sino también como una coyuntura favorable para la experimentación de combinatorias insospechadas y para la invención de configuraciones culturales más estimulantes. Es cierto que el choque entre instintos y criterios de valor antitéticos, característico de una «época de disolución», puede terminar de agotar al «hombre de las culturas tardías», cuya «aspiración más honda consiste en que la guerra que él es finalice alguna vez» (JGB: KSA V 120). Sin embargo, también puede actuar «como un atractivo y un estimulante más de la vida» (ibid. 121). En medio de este horizonte abierto, Nietzsche llega incluso a relativizar el valor de toda cultura aristocrática y reconocer asimismo los méritos de esta cultura semibárbara en la que nos hallamos inmersos:

«Ese sentido histórico que nosotros los europeos reivindicamos como nuestra peculiaridad lo ha traído a nosotros la encantadora y loca semibarbarie en que la mezcolanza democrática de estamentos y razas ha precipitado a Europa, -el siglo XIX ha sido el primero en conocer ese sentido como su sexto sentido. El pasado de cada forma y de cada modo de vivir, de culturas que antes se hallaban duramente yuxtapuestas, superpuestas, desemboca, gracias a esa mezcolanza, en nosotros, 'almas modernas', a partir de ahora nuestros instintos corren por 
todas partes hacia atrás, nosotros mismos somos una especie de caos -: finalmente, como hemos dicho, 'el espíritu' descubre en esto su ventaja. Gracias a nuestra semibarbarie de cuerpo y de deseos tenemos accesos secretos a todas partes, accesos no poseídos nunca por ninguna época aristocrática, sobre todo los accesos al laberinto de las culturas incompletas y a toda semibarbarie que alguna vez haya existido en la tierra» (ibid. 158).

La vuelta atrás no tiene la significación de un rescate de la pureza del pasado, sino la de un juego de disfraces y una contaminación productiva entre herencias diversas para ensayar nuevas invenciones. El sentido histórico que impregna la crítica genealógica nietzscheana a partir de Humano, demasiado humano modifica drásticamente el vitalismo de obras como El nacimiento de la tragedia o la Segunda intempestiva y así, a la vez que liquida toda nostalgia de edades doradas, desborda la lectura estrictamente biologicista del criterio de la 'utilidad para la vida'. Dado que para Nietzsche no cabe apelar a la estabilidad de un instinto de conservación ni a ninguna otra clase de «principios teleológicos superfluos» (ibid. 27-28), la utilidad, «en el sentido de la biología darwiniana ${ }^{48}$ queda puesta en entredicho. Con el nombre de vida alude el filósofo a complejos procesos de asimilación y crecimiento donde no existe una única matriz impulsora, sino un entramado de fuerzas que tratan de desplegarse e intensificarse, siendo la autoconservación una consecuencia más de este potenciamiento, antes que una finalidad. De ahí que, por más que Nietzsche haya adoptado a veces argumentos de la fisiología de su tiempo, su enfoque le resulte demasiado estrecho. Propiamente, será por éste y por motivos similares por lo que la preferencia de las obras 'intermedias' por la ciencia acabará cediendo terreno al arte como espacio idóneo a partir del cual suscitar la transvaloración de los valores. La mirada científica al mundo sigue orientándose por unos parámetros excesivamente estabilizadores (conservación, utilidad), restrictivos de la dinámica siempre desbordante de energía en el devenir de fuerzas contrapuestas, que, en cambio, la mirada trágico-dionisíaca del arte tiende a preservar. De hecho, incluso la intelección del primitivo impulso a la formación de metáforas como un mero mecanismo adaptativo de supervivencia supone

${ }^{47}$ Cf. v.g. KSA XIII 65-66: 14[65], de primavera de 1888.

${ }^{48}$ KSA XI 309. Son varios los aforismos encabezados por el rótulo de «Anti-Darwin», entre ellos el aforismo 14 de las «Incursiones de un intempestivo» de Crepúsculo de los ídolos, donde Nietzsche replica a la escuela darwiniana que lo más característico de la existencia no es la situación calamitosa de lucha por la vida, sino el estado de exuberancia, prodigalidad absurda y lucha por el poder. «No se debe confundir a Malthus con la naturaleza», añade. Su polémica contra estas concepciones del instinto de conservación prolongan su crítica del concepto schopenhaueriano de voluntad. Cf. v.g. el aforismo 22 , en el que Nietzsche aduce que la naturaleza contradice la tesis de Schopenhauer de que la belleza niega el 'foco de la voluntad', la sexualidad. Son, por el contrario, los estados de vigor animal los que el arte nos recuerda, potenciando en nosotros el gusto por la vida. De ahí que en el embellecimiento del animal humano, éste no tenga que ser negado ni suprimido: «aquel 'animal salvaje' no ha sido matado en absoluto, vive, prospera, 
una lectura demasiado apegada a la vulgata utilitarista. En sus consideraciones finales sobre el arte como poder generador de ficciones estimulantes para la vida, especialmente necesario en un tiempo en que el mundo se nos ha vuelto más inmenso y abierto a la infinitud de perspectivas que nunca, Nietzsche rebasa aquel planteamiento en favor de una 'psicología del artista', que localiza en la embriaguez de la que van seguidos todos los afectos intensos, así como en los sentimientos concomitantes de plenitud e incremento de las fuerzas, una condición fisiológica previa, que lleva a metamorfosear el mundo e 'idealizarlo' (KSA VI 116). A través de su estética fisiológica, Nietzsche retoma, pues, uno de los temas predilectos del primer romanticismo: la creación artística como reflejo de la potencia infinitamente creadora de la naturaleza.

El de Nietzsche es, por tanto, un itinerario consecuente con las tesis de la Frühromantik, que, no obstante, una vez deshechos los equívocos metafísicorománticos de juventud, radicaliza su componente nihilista hasta el completo abandono de toda nostalgia de los orígenes. La idealización y divinización a las que se refiere Nietzsche en numerosos pasajes como éste no están disociadas, pues, de la tarea de desdivinización que el filósofo-artista debe seguir practicando sobre todas las sombras de Dios. Por eso precisa en otro apartado de Crepúsculo de los ídolos titulado «Progreso, en el sentido en que yo lo entiendo»: «También yo hablo de una 'vuelta a la naturaleza' [Rückkehr zur Natur], aunque propiamente no es un regresar [Zurückkehren)], sino un ascender [Hinaufkommen] - un ascender a la naturaleza y a la naturalidad elevada, libre, incluso terrible, que juega, que tiene derecho a jugar con grandes tareas...» (KSA VI 150).

No hay vuelta sino como rememoración del impulso metaforizante que está a la base de nuestras verdades, como recordatorio de la posibilidad de reactivarlo en la situación presente, para emprender «nuevos viajes de descubrimiento». Nietzsche denomina a este regreso crítico, reflexivo, al origen demasiado humano de nuestras construcciones de sentido, 'genealogía'. La genealogía no pretende devolvernos a un estado anómico de expresividad primaria de los instintos, desligado de toda constricción lógico-conceptual, entre otros motivos porque ha sido precisamente el cultivo de dichas constricciones y de la sofisticada crueldad de una desmedida voluntad de verdad lo que ha permitido que nos preguntemos por la razón de nuestras razones y descubramos su olvidado trasfondo de sinrazón; no trata de licenciar al concepto y sustituirlo por la intuición estética, sino de advertir de la ilegitimidad de practicar una cesura fuerte, dualista, entre los dominios del arte y la verdad. Al comprender que nuestras verdades son el resultado de una lejana labor mitopoiética, nos privamos de énfasis metafísicos al mismo tiempo que asumimos la responsabilidad de ser nosotros «los coloristas del mundo» (KSA II 37). A esta situación ya de siempre interpretativa de la existencia y abierta a la invención de nuevos significados es a lo que se regresa en todo caso, a la posibilidad misma de otro inicio. De 
este modo, Nietzsche pone de manifiesto uno de los efectos buscados por el recurso de los primeros románticos a una Naturaleza irreductible al patrón racionalista -deconstruir las tramas de significación habituales, establecer un distanciamiento irónico que permita la reinvención de sentido- insistiendo en la dimensión de crítica cultural que dicho recurso, tan presente en la praxis estética de la Frühromantik, posee, esto es, subrayando el hecho de que una operación semejante sólo puede ejecutarse sobre la base del suelo histórico de positividad suministrado por el presente. No hay mirada directa al eterno absoluto, sino distorsión intempestiva de la óptica actual. Esta disolución de la formas establecidas, que permite la irrupción de novedad, no les niega valor por completo, como ocurría en el caso del nihilismo reactivo de un Jacobi, antes bien, reivindica en su incesante transición, en su pasar, transformarse y perecer, el 'lugar' en el que centellea la verdad de la apariencia. La adopción nietzscheana de un pensar que experimenta con la verdad y aspira a transformarnos, reclamando de nosotros la fuerza para soportar la más pesada carga y afirmar, pese a todo, la existencia, evoca directamente el contexto de esta réplica. La doctrina del eterno retorno, propuesta por Nietzsche como distorsión del tiempo lineal, no sólo formula expresamente su continuidad con el intento de los jóvenes idealistas y primeros románticos de repensar un panteísmo que sirviera para proclamar un sí sin reservas a este mundo ${ }^{49}$. También apela a un tipo singular de creencia, más básica que toda fe en la verdad, que todo instintivo tener-por-verdadero, en el que se recoge el envite del salto mortal jacobiano y, en lugar de orientarlo hacia un inexistente más allá, se lo destina a la tierra para afirmar finalmente que, aun con toda su dosis de azar y sinsentido, «la vida debe inspirar confianza».

únicamente -se ha divinizado» (MBM: KSA V 166).

${ }^{49}$ Sólo que la depuración de la instancia teológica lleva a Nietzsche a presentar este pensamiento como una nueva versión del panteísmo, contraria a la proyección spinoziana de atributos lógico-morales al deus sive natura, que, no obstante, conserva su voluntad básica de afirmar la existencia: «Se entiende entonces que lo que aquí se busca es una antítesis del panteísmo: puesto que el 'Todo perfecto, divino, eterno' obliga igualmente a una creencia en el 'eterno retorno'. Pregunta: ¿acaso se ha imposible, junto con la moral, esta postura panteísta de Sí a todas las cosas? En el fondo, sólo el dios moral está superado. ¿Tiene sentido concebir un dios 'más allá del Bien y del Mal'? ¿Sería posible un panteísmo en este sentido? ¿Excluimos del proceso la representación de la finalidad y afirmamos pese a ello el proceso? - Éste sería el caso, si dentro de ese proceso, en cada uno de sus momentos, se alcanzara algo -y siempre lo mismo. Spinoza se ganó una posición afirmativa semejante en la medida en que cada momento posee una necesidad lógica: y triunfó con su fundamental instinto lógico sobre una tal constitución del mundo» KSA XII 214: 5[71]. Se trata del epígrafe octavo del extenso fragmento titulado «El 